\title{
Mechanical Properties of $\mathrm{UO}_{2}$ Thin Films under Heavy Ion Irradiation using Nanoindentation and Finite Element Modeling
}

\section{Mohamed S. Elbakhshwan*, Yinbin Miao, James F. Stubbins, Brent J. Heuser}

Department of Nuclear, Plasma, and Radiological Engineering, University of Illinois Urbana Champaign

\section{$\underline{\text { Abstract }}$}

The mechanical response of $\mathrm{UO}_{2}$ to irradiation is becoming increasingly important due to the shift to higher burn-up rates in the next generation of nuclear reactors. In the current study, thin films of $\mathrm{UO}_{2}$ were deposited on YSZ substrates using reactive-gas magnetron sputtering. Nanoindentation was used to measure the mechanical properties of the as-grown and irradiated films. Finite element modeling was used to account for the substrate effect on the measurements. In order to study the effect of displacement cascades accompanying gas bubbles, $5000 \AA \mathrm{UO}_{2}$ films were irradiated with $600 \mathrm{keV} \mathrm{Kr}{ }^{+}$ions at $25^{\circ} \mathrm{C}$ and $600^{\circ} \mathrm{C}$. These irradiation conditions were used to confine radiation damage effects and implanted gas within the film. Results showed an increase in the film hardness and yield strength with dose, while elastic modulus initially decreased with irradiation and then kept increasing with dose. The change in hardness and elastic modulus is attributed to the introduction of gas bubbles and displacement cascade damage. Irradiation at $600^{\circ} \mathrm{C}$ resulted in a decrease in the hardness and elastic modulus after irradiation using $600 \mathrm{keV} \mathrm{Kr}{ }^{+}$at a dose of $1 \mathrm{E} 14 \mathrm{ions} / \mathrm{cm}^{2}$. Both hardness and elastic modulus then increased with irradiation dose. This behavior is attributed to recrystallization during irradiation at $600^{\circ} \mathrm{C}$ and the formation of nanocrystallite regions with diameter and density that increase with dose. The calculation of the critical resolved shear stress (CRSS) demonstrated that nanocrystals are the primary cause for film hardening based on the Orowan hardening mechanism.

Keywords: $\mathrm{UO}_{2}$, thin films, nanoindentation, mechanical properties, heavy ion irradiation

*Corresponding author:

Electronic mail: elbakhs1@illinois.edu 


\section{Introduction}

As the nuclear industry moves toward high fuel burn-up, there is a need for advancing our knowledge of the mechanical behavior of nuclear fuels to assure the fuel stability and durability. At the same time, pellet cladding interaction depends on the cladding mechanical properties as well as the level of stresses introduced in the fuel due to the fission gas release. Stresses within the pellet may induce cracks that depend on the fuel thermal expansion, thermal conductivity and the elastic properties [1 - 5].

Indentation techniques have been applied to study the effects of irradiation on the mechanical properties of $\mathrm{UO}_{2}$. Spino et al. used microhardness to the study of the change in elastic/plastic properties of $\mathrm{UO}_{2}-\mathrm{LWR}$ fuel pellets, irradiated in power reactor to a burn-up rate ranging from 40 to $100 \mathrm{GWd} / \mathrm{t} \mathrm{M}$ [6]. The entire fuel rod hardness increased as the average burn-up increased up to $67 \mathrm{GWd} / \mathrm{t} \mathrm{M}$, but it decreased again as the average burn-up increased to $80 \mathrm{GWd} / \mathrm{t} \mathrm{M}$ due to the healing of accumulated radiation damage. The periphery of the fuel rod softened and the depth of the rim zone increased with the average burn-up following the porosity build up profile [6]. In addition, material recrystallization at the pellet edge was observed [7, 8]. Kim et al. applied Knopp indentation and found similar behavior with neutron irradiation, that the $\mathrm{UO}_{2}$ hardness increased with neutron dose up to a certain point then decreased $[9,10]$, and explained that again by the annihilation of the defects produced by irradiation.

The change in the $\mathrm{UO}_{2}$ elastic modulus was studied as a function of different parameters; porosity concentration, stoichiometry, grain size, temperature, and dopant concentration [3,4]. However limited data are available regarding the changes due to irradiation [3, 4]. Laux et al. studied the change of elastic modulus of nuclear fuel pellets and simulated spent fuel (SIMFUEL) with burn-up rate using acoustic microscopy [3]. The elastic modulus of SIMFUEL and irradiated fuel pellets decreased by about $25 \%$ as the burn- up increased up to $100 \mathrm{GWd} / \mathrm{MTU}$. Beyond that, there is no data available for the irradiated fuel pellets but the elastic modulus of SIMFUEL stabilized [3]. On the other hand, Pujol et al. founded that the elastic modulus of simulated fuel increased with increasing the fuel burn-up [4]. Simulated fuel is $\mathrm{UO}_{2}$ that has been mixed with various additives to simulate the compositional effects of the burn-up. Two different methods were used to calculate the elastic modulus; X-ray diffraction under high pressure and Knopp indentation test. Both measurements show that the elastic modulus increased with the burn-up. Calculated elastic constant values from indentation tests increase smoothly with burn-up, and saturate after burn-up of about $100 \mathrm{GWd} / \mathrm{MTU}$, while the data obtained from the compressing test increase lineally with burn-up.

In general, there is limited amount of data available about the mechanical properties of $\mathrm{UO}_{2}$ after irradiation [3 - 10], and some of them are contradicting especially regarding the changes in the elastic modulus [4]. Therefore, this work is intended to provide a systematic study of the change in $\mathrm{UO}_{2}$ 
mechanical properties under heavy ion irradiation using different techniques and methods to study this phenomena; namely thin film geometry and nanoindentation.

Thin film geometry allows for control over several properties such as microstructure, oxygen stoichiometry, and impurity concentrations. This ability permits the advancement of the knowledge and understanding of the nanoscale behavior of uranium oxide under different irradiation and temperature conditions, which can lead to better burn-up performance. Nanoindentation has proved to be a useful technique to determine the mechanical properties for different non-nuclear materials [11 - 13] as well as nuclear materials such as; YSZ [14, 15], $\mathrm{CeO}_{2}$ and $\mathrm{UO}_{2}$ [16 - 18], simulated nuclear fuel [19], and irradiated materials $[14,15,20,21]$. Nanoindentation is suitable for investigating the mechanical properties of thin films due to the ability to apply loads in the range of $10^{-9} \mathrm{~N}$ and limiting the depth of penetration to nanometers $[20,22]$. In the current study, nanoindentation was used to study the change in mechanical properties of $\mathrm{UO}_{2}$ thin films under different irradiation damage and temperature conditions. However, the substrate can affect the measurements [22]; therefore finite element modeling (FEM) was used to account for the substrate effect on the nanoindentation measurements [21]. In addition, FEM provides a method to estimate the mechanical properties of the irradiated $\mathrm{UO}_{2}$ film layers independently from the unirradiated layers.

This work represents a systematic study regarding the change in the mechanical properties of $\mathrm{UO}_{2}$ under heavy ion irradiation using single crystal thin films deposited on YSZ substrates. The irradiation conditions were chosen to assure that the radiation damage effect (displacement cascades and implanted gas bubbles) are confined within the $\mathrm{UO}_{2}$ film, with no defects introduced into the substrate material. Finally, this study is focusing on using thin films of $\mathrm{UO}_{2}$ as a surrogate for the bulk nuclear fuel that can be used to obtain similar and relevant results in better controlled conditions and without the dealing with large quantities of nuclear materials.

\section{Experimental Methods}

\subsection{Film Deposition, Characterization, and Irradiation}

Thin films of $\mathrm{UO}_{2}$ were deposited on single crystal YSZ (8 \%mole $\mathrm{Y}_{2} \mathrm{O}_{3}$ ) substrates using reactive gas magnetron sputtering technique $[23,24]$. The sputtering was performed in current control mode, in which the ion current was fixed at $0.056 \mathrm{~mA}$, with the power and voltage were maintained at approximately $20 \mathrm{~W}$ and $352 \mathrm{~V}$ respectively. Before the deposition process, the substrate was annealed at $400^{\circ} \mathrm{C}$ for two hours followed by two hours annealing at $750^{\circ} \mathrm{C}$. During the deposition process, the temperature was fixed at $700^{\circ} \mathrm{C}$ and the oxygen partial pressure was $10^{-5} \mathrm{~Pa}$. The substrate was rotated at 
60 RPM to insure uniform heat distribution and growth rate $(3.4 \AA / \mathrm{sec})$. The final thickness of the films is $5000 \AA$ estimated by Rutherford backscattering spectroscopy (RBS). X-ray diffraction measurements (XRD) were performed using PANalytical / Philips X'pert MRD X-ray instrument using Cu K- $\alpha 1$ source producing X-rays with wavelength of $1.54056 \AA$. The measurements performed using high-resolution parallel beam configuration with hybrid mirror and 2-bounce monochromator and high-speed line detector. XRD measurements show that the film has a single $\left(\begin{array}{lll}2 & 0 & 0\end{array}\right)$ growth orientation as shown in Figure 1. The $\mathrm{UO}_{2}$ thin film structural characterizations were explained in more details elsewhere [24].

The microstructure of as-grown and irradiated $\mathrm{UO}_{2}$ thin films was investigated using JEOL 2010 with $2010 \mathrm{LaB}_{6}$ filament transmission electron microscope (TEM) which is optimized for diffraction contrast imaging and capable of sample tilt along two perpendicular axes. TEM specimens were prepared by mechanically ground the YSZ side to about $50 \mu \mathrm{m}$ thickness using diamond lapping films. Then, ion milling with 3-5 keV Ar ions was used to thin the specimens to 30-60 nm thickness. Cross sectional TEM images revealed that $\mathrm{UO}_{2}$ films were deposited on the YSZ substrate in columnar morphology extended from the film-substrate interface to the film surface, as shown in Figure 2. This columnar structure is common in the thin film deposition and was noticed in several studies [25 - 27]. Plan view TEM image show that $\mathrm{UO}_{2}$ film has several dislocation lines which formed due the misfit between the film and substrate lattices $[25,28,29]$, as shown in Figure 3. Finally, Thin films were irradiated with $600 \mathrm{keV} \mathrm{Kr}^{+}$ ions at doses of $1 \mathrm{E} 14,5 \mathrm{E} 14,1 \mathrm{E} 15,1 \mathrm{E} 16$ and $1.5 \mathrm{E} 16$ ions $/ \mathrm{cm}^{2}$ at $25^{\circ} \mathrm{C}$ and $600^{\circ} \mathrm{C}$ using High Voltage Engineering Van de Graaff accelerator. Figure 4 shows the $\mathrm{Kr}^{+}$concentrations and differential energy deposition estimated by SRIM calculations [30]. $\mathrm{Kr}^{+}$ions had a maximum range of about $4000 \AA$ in $\mathrm{UO}_{2}$ with peak concentration at $1629 \AA$. Irradiation results at $600^{\circ} \mathrm{C}$ were compared to one sample labelled "annealed sample" that was exposed to the same thermal history as the sample irradiated with dose of $1 \mathrm{E} 16 \mathrm{ions} / \mathrm{cm}^{2}$. It was kept at $600^{\circ} \mathrm{C}$ for approximately 90 minutes.

\section{$\underline{2.2}$ Nanoindentation and Finite Element Modeling}

Nanoindentation measurements were performed using Hysitron TI 950 TriboIndenter, which provides a precise control over the applied load and the indentation depth and can apply load over the range of $30 \mathrm{nN}$ to $10 \mathrm{~N}$. All the measurements were performed at load control mode in which the maximum applied load was fixed at $5000 \mu \mathrm{N}$. Each sample was indented using Berkovick indenter.

The experiment was performed into two steps; the loading step, when the load is applied to push the indenter into the material at a loading rate of $1 \mathrm{mN} / \mathrm{sec}$ until it reaches the maximum specified load $(5000 \mu \mathrm{N})$. Then the indenter is drawn back to its original position during the unloading step. It is worth mentioning that, the source of errors in the nanoindentation measurements are mainly coming from 
estimation of the contact area between the indenter and the material; and it is generally accepted to be about $5 \%$ or less [20]. For each measurement, the material is indented at different nine different positions and the average value is used to provide statistically acceptable data. In the same time, the standard deviation (shown with the data below) used to show the spread of the data and assure its consistency.

Finite element modeling was used to simulate the nanoindentation process using the ABAQUS finite element program [31]. The film had a thickness of $0.5 \mu \mathrm{m}$, a width of $3 \mu \mathrm{m}$, while the substrate had a thickness of $2.54 \mu \mathrm{m}$ and a width of $3 \mu \mathrm{m}$. The film-substrate unit was divided into small elements with density increased in the high deformation area and decreased on the boundaries to save computational time. The smallest element size was $15 \times 20 \mathrm{~nm}^{2}$ and was located just under the indenter, with a total of 3016 elements, as shown in Figure 5. The lower bottom of the substrate was fixed with no displacement or rotational movement, while the nodes on the axisymmetric line in the film and substrate as well as the indenter were allowed to move in the vertical direction only. The interface connection between film and substrate was assumed perfect, with no sliding. No direct force acted on the substrate and all the plastic deformation was confined to the film as verified by FEM. Therefore, the substrate was modeled as an elastic medium with the same elastic properties from the modeling of YSZ substrate $(E=175 \mathrm{GPa}, \mathrm{v}=0.3$ ) [32].

The indenter was described as rigid body that could not be deformed during the simulation. This is a valid approximation since the indenter is made out of diamond that shows very small elastic response (elastic modulus equal to $1140 \mathrm{GPa}$ ); this approximation might not be valid if the material is very hard such as diamond-like carbon [20]. All materials were simulated using classical metal plasticity model in ABAQUS [31], in which the mass density, Poisson's ratio, elastic modulus, and yield strength of each material are required. Work hardening can be modeled by introducing the work hardening exponent, but since both YSZ and UO2 are ceramics, it was not included into the simulation. The mass density and Poisson's ratio were fixed in all simulations and materials were assumed to be locally isotropic since the probing area of nanoindentation is very small.

The $\mathrm{UO}_{2}$ film was modeled as an elastic-plastic material with density of $10.97 \mathrm{~g} / \mathrm{cm}^{3}$ and Poisson's ratio of 0.3 . The simulation used arbitrary values for elastic modulus and yield strength which were allowed to change to achieve the best fit for the experimental curve. Results showed that the elastic modulus is lower than values found in the literature [16], which can be attributed to the difficulty in simulating the exact shape of the indenter tip, and the anisotropy of the elastic modulus [32]. On the other hand, the FEM estimation of yield strength is much larger than the literature value for bulk $\mathrm{UO}_{2}$ [33]. These differences are expected in thin films, and were observed previously in $\mathrm{Cu}$ thin films deposited on Si [34]. The high strength of thin films compared to bulk samples is attributed to the small crystal size and high dislocation density in the thin films, as shown in Figure 3. The density was calculated to be 
1.38E14 dislocations $/ \mathrm{m}^{2}$ which is even higher than the values reported for irradiated fuel pellets up to burn up of $40 \mathrm{GWD} / \mathrm{t}$ [35]. In addition, the substrate constrains the dislocation motion in thin film geometry [36]. In order to estimate the film hardness, a separate simulation was performed on a bulk simulated sample of $\mathrm{UO}_{2}$. This simulation used the elastic modulus and yield strength values estimated from the best fit of experimental data.

In this study, $5000 \AA \mathrm{UO}_{2}$ films were irradiated with $600 \mathrm{keV} \mathrm{Kr}^{+}$at doses ranging from $1 \mathrm{E} 14$ to $1.5 \mathrm{E} 16$ ions $/ \mathrm{cm}^{2}$. According to SRIM calculations [30], the $\mathrm{Kr}^{+}$ion concentration associated with the deposition energy was confined within $4000 \AA$ of the film thickness, as shown in Figure 4. Three layers were used in the FEM simulation; the first layer extended from the film surface up to a depth of $4000 \AA$. The unirradiated film represented the remaining portion of the film to the film-substrate interface, and the substrate was simulated as the third layer. The top two layers of the film were divided into small elements. The smallest element size just under the indenter tip was $15 \times 20 \mathrm{~nm}^{2}$, giving a total number of elements in the irradiated and unirradiated film layers of 1541 and 335 elements respectively, while the total number of elements in the substrate was 1340.

\section{$\underline{\text { 3. Results }}$}

$\mathrm{UO}_{2}$ thin films with thicknesses of $5000 \AA$ were irradiated with $600 \mathrm{keV} \mathrm{Kr}^{+}$ions over a dose range of $1 \mathrm{E} 14$ to $1.5 \mathrm{E} 16 \mathrm{ions} / \mathrm{cm}^{2}$ at $25^{\circ} \mathrm{C}$ and at $600^{\circ} \mathrm{C}$, all irradiation parameters estimated from SRIM calculations [30] are summarized in Table 1. Nanoindentation was used to measure the change in mechanical properties and then results were fitted using FEM to account for the substrate effect. The results are summarized as follow:

\subsection{Irradiation at $25^{\circ} \mathrm{C}$}

Figure 6 shows the load-displacement curves for the as-grown film as well as the irradiated films. For the same maximum applied load $(5000 \mu \mathrm{N})$, all irradiated films have a smaller penetration depth compared to the as-grown film, which implies that the material is hardening with irradiation. Figure 7 shows the FEM best fitting for unirradiated $5000 \AA \mathrm{UO}_{2}$ thin film during loading and unloading stages and the simulation fits the experimental data well in both stages.

FEM results show that the elastic modulus decreased with initial irradiation, then it increased at dose of $5 \mathrm{E} 14$ ions $/ \mathrm{cm}^{2}$ and followed by slight reduction at dose of $1 \mathrm{E} 15 \mathrm{ions} / \mathrm{cm}^{2}$, but the elastic modulus kept increasing afterward with irradiation dose, as shown in Figure 8. Overall, the initial irradiation led to

reduction in the elastic modulus, however further irradiation led to the increase of the elastic modulus by approximately $6 \%$. At the dose of $1 \mathrm{E} 16$ ions $/ \mathrm{cm}^{2}$, the elastic modulus reached to a value of $175 \mathrm{GPa}$, 
about 3\% lower than the original value before irradiation. For yield strength and hardness, both properties increased with initial irradiation dose as shown in Figures 9 and 10 respectively. Yield strength increased substantially after irradiation at $5 \mathrm{E} 14$ ions $/ \mathrm{cm}^{2}$ then decreased at $1 \mathrm{E} 15$ ions $/ \mathrm{cm}^{2}$ and finally slowly increased with dose. Hardness followed the same trend as yield strength but with less dramatic changes in early stages of irradiation. Overall, the yield strength and hardness increased approximately by $17 \%$ and $13 \%$ with irradiation respectively. All elastic modulus, yield strength, and hardness results estimated by FEM are summarized in Table 2.

Plan-view TEM images for film irradiated with $600 \mathrm{keV} \mathrm{Kr}^{+}$ions at a dose of $1 \mathrm{E} 16$ ions $/ \mathrm{cm}^{2}$ at $25^{\circ} \mathrm{C}$ show round features, with size of $1.18 \pm 0.1 \mathrm{~nm}$ that have an opposite contrast in over and under focus imaging conditions, are shown in Figure 11. This is an indication of the formation of bubbles or voids in the film due to the $\mathrm{Kr}^{+}$ions irradiation [37]. The increase in the hardness and the yield strength occurs via the formation of gas bubbles and dislocation loops into the $\mathrm{UO}_{2}$ matrix that increase with the irradiation dose. These bubbles and loops impede the dislocation motion and so harden the irradiated films [38 - 40].

Elastic modulus represents a measurement of the material resistance to displacement of adjacent atoms [41]. The change in elastic modulus is always related to the change in the interatomic bonding, mainly due to the presence of point defects. The change in elastic modulus with irradiation can be due to two effects. First, the presence of vacancies or interstitial defects will change the total number and strength of the interatomic bonds in the system. Second, the point defects induce lattice expansion and associated change in bond forces [42, 43]. The reduction of elastic modulus with point defects has been reported for fluorite-structure in pure and gadolinium-doped $\mathrm{CeO}_{2}$ by measuring the change in elastic modulus with different oxygen partial pressure at $800^{\circ} \mathrm{C}$ using nanoindentation $[43,44]$. Therefore the initial decrease in elastic modulus after irradiation with $1 \mathrm{E} 14 \mathrm{ions} / \mathrm{cm}^{2}$ is caused by the introduction of point defects and dislocation loops which led to the formation of large number of dislocation in the irradiated film (3.63E14 dislocations $\left./ \mathrm{m}^{2}\right)$ as shown in Figure 11. If the dislocation density is high enough, newly formed point defects and displacement cascades are more likely to react with the existing defect clusters and erase them [38 - 40]. Therefore, further irradiation at higher irradiation doses led to the increase in the elastic modulus as shown in Figure 8.

\subsection{Irradiation at $600^{\circ} \mathrm{C}$}

Figure 12 shows the load-displacement curves for $\mathrm{UO}_{2}$ thin films irradiated with $600 \mathrm{keV} \mathrm{Kr}^{+}$at $600^{\circ} \mathrm{C}$ in addition to the as-grown sample and one annealed sample. For the same maximum applied load $(5000 \mu \mathrm{N})$, the annealed sample has a higher penetration depth than the reference sample. This implies that, the sample was softened with annealing due to the recovery of material defects. For the sample 
irradiated with a dose of $1 \mathrm{E} 14$ ions $/ \mathrm{cm}^{2}$, there was a slight decrease in hardness, but as the irradiation dose increased, the yield strength and hardness increased systematically with dose, as shown in Figures 9 and 10 and as summarized in Table 2.

In order to explain the material behavior under irradiation, TEM plan view images were used to investigate the microstructure evolution. Figures 14 and 15 show that nanocrystallites formed in $\mathrm{UO}_{2}$ thin films irradiated with $600 \mathrm{keV} \mathrm{Kr}{ }^{+}$ions at a dose of $1 \mathrm{E} 14$ and $1 \mathrm{E} 16$ ions $/ \mathrm{cm}^{2}$ at $600^{\circ} \mathrm{C}$ with average size of 3 and $2 \mathrm{~nm}$ respectively. The nanocrystallites number density and volume fraction increased with irradiation dose as shown by the increase of the intensity of the diffraction rings. The diameter of the nanocrystallites diffraction rings are smaller than the distance between the $\left(\begin{array}{lll}0 & 0\end{array}\right)$ diffraction spots. This is attributed to the change in orientation of the nanocrystallites. The interplanar distance for the newly formed ring was found to be $3.131 \AA$, very close to the interplanar distance for $\left(\begin{array}{lll}1 & 1 & 1\end{array}\right)$ crystallographic orientation with 3.148 [45]. TEM images show that gas bubble was formed after irradiation with 600 $\mathrm{keV} \mathrm{Kr}{ }^{+}$ions at a dose of $1 \mathrm{E} 14$ ions $/ \mathrm{cm}^{2}$ at $600^{\circ} \mathrm{C}$, as shown in Figure 16 . The measured bubble density and volume fraction are less than bubbles formed after irradiation at $25^{\circ} \mathrm{C}$, which is attributed to the recrystallization and the associated formation of nanocrystallites observed at the $600^{\circ} \mathrm{C}$.

Figure 8 shows that the elastic modulus decreased by approximately $9 \%$ after annealing at $600^{\circ} \mathrm{C}$. This reduction is due to the thermal expansion [46, 47] of the lattice and so the increase in the lattice parameter of the $\mathrm{UO}_{2}$ thin film by annealing from 5.470 to $5.478 \AA$ as measured by XRD and shown in Figure 13. After the irradiation with $1 \mathrm{E} 14$ ions $/ \mathrm{cm}^{2}$, the elastic modulus decreased compared to the annealed film due to the introduction of point defects $[42,48]$. As the irradiation dose increased to 1.5E16 ions $/ \mathrm{cm}^{2}$, the elastic modulus systematically increased due to the recrystallization which led to the annihilation of point defects and dislocation loops [42, 43, 49, 50], as shown in Figure 8 and summarized in Table 2.

\section{Discussions}

In general terms, ceramic materials are hard and deform in a brittle manner. However they can deform plastically if the stress and temperature levels are allowing dislocations to be mobile [51]. Several studies have focused on the deformation mechanisms in $\mathrm{UO}_{2}$ at different conditions and temperatures. Keller et al., found that the movement of screw dislocations control the deformation of single crystal $\mathrm{UO}_{2}$ during microhardness testing at $600^{\circ} \mathrm{C}$ [52]. Ashbee and Yust suggested that the plastic deformation of superstoichiometric $\mathrm{UO}_{2}$ is a combination of $\mathrm{UO}_{2}$ and $\mathrm{U}_{4} \mathrm{O}_{9}$ attached to the active slip systems [53]. In addition, Fossati et al., applied molecular dynamics to simulate dislocation motion in $\mathrm{UO}_{2}$ and found that the critical stress for dislocation glide is decreasing with temperature [54]. These studies confirmed that 
plastic deformation exists in $\mathrm{UO}_{2}$ and so applying Orowan mechanism $[38,55,56]$ model is relevant to understand the hardening mechanisms in $\mathrm{UO}_{2}$.

Nanocrystallites, bubbles and precipitates, harden the material by acting as obstacles for dislocation motion $[38,55]$. The critical resolved shear stress (CRSS) for Orowan hardening is given by [56 - 58]:

$$
\begin{aligned}
& \tau=0.9 \frac{\mu b\left[\ln \left(2 / b\left(1 / L_{P}+4 / \pi d\right)\right)\right]^{1.5}}{2 \pi(1-v)^{0.5} L_{p}\left[\ln \left(L_{p} / b\right)\right]^{0.5}} \\
& L_{p}=d\left[(\pi / 6 f)^{0.5}-(\pi / 4)\right]
\end{aligned}
$$

due to the presence of an array of obstacles in the path of a line dislocation. In these equations, $\tau$ is the critical resolved shear stress, $\mu$ is the shear modulus, $b$ is the Burgers vector, $v$ is the Poisson's ratio, $\mathrm{L}_{\mathrm{p}}$ is the edge to edge spacing between randomly spaced obstacles, $\mathrm{d}$ is the bubble diameter, and $f$ is the bubble volume fraction. The shear modulus of $\mathrm{UO}_{2}$ was found to be $76.3 \mathrm{GPa}$ [59] and the Burgers vector for (2 00 ) single orientation film was estimated to be $0.274 \mathrm{~nm}$. The CRSS formed due to the formation bubbles and nanocrystallites was calculated and summarized in Tables 3 and 4.

Gas bubbles implanted in all films irradiated at $25^{\circ} \mathrm{C}$, act as obstacles for the dislocation motion within the films. When an external stress is applied, it causes the dislocation lines to bow between the obstacles/bubbles until the dislocation segments join and annihilate each other. Orowan hardening can be used to estimate the critical resolved shear stress (CRSS) for an array of obstacles based on the assumption that these obstacles are uniformly distributed in the material $[57,58,60]$. The CRSS was found to increase with the obstacles volume fraction, which follows the increase in irradiation dose as summarized in Table 3. In the same time, the yield strength was found to increase with the dose too as summarized in Table 2. The yield strength was plotted against the CRSS and found to increase linearly with slope of 1.6 as shown in Figure 17. The intercept represents the yield strength of the unirradiated $\mathrm{UO}_{2}$ films (at CRSS $=0$ ) [58] and the value of $8.7 \mathrm{GPa}$ is about $16 \%$ higher than the values estimated by FEM as summarized in Table 2. This difference may be due to the poor fitting because of limited number of data points.

Irradiation of the films at $600^{\circ} \mathrm{C}$ led to a systematic increase in hardness with dose. Initially, the film hardness and yield strength decreased with annealing, as well as after the initial irradiation. Further irradiation increased the hardness and yield strength systematically with dose. TEM showed the formation of nanocrystallites associated with the irradiation at $600^{\circ} \mathrm{C}$ which is a characteristic signature of recrystallization attributed to the release of internal energy of the system [49]. The nanocrystallite act as obstacles for the motion of dislocations and induce hardening. Orowan hardening was employed to estimate CRSS as summarized in Table 4. Gas bubbles were observed with TEM images and had an 
approximate diameter of 0.7 nanometers. These bubbles are smaller than those formed during irradiation at $25^{\circ} \mathrm{C}$. It is believed that recrytallization led to the loss of some of the implanted gases [50]. It is clear that the induced strength from the nanocrystallites is much larger than the strength induced by the bubbles. This implies that, the hardening of irradiated $\mathrm{UO}_{2}$ films at $600^{\circ} \mathrm{C}$ is primarily driven by the formation of the nanocrystallites in the film.

It is worth mentioning that, the mechanism of Orowan hardening is based on the assumption that obstacles are uniformly distributed throughout the material $[38,55,56]$. This assumption is acceptable for bubbles formed in the irradiated films due to the spread of bubble positions. On the other hand, nanocrystallites with different orientations can be connected together in clusters as shown in Figures 14 and 15. This is one point in which the mechanism of Orowan hardening may not be able to describe accurately due to the underlying complexity of the microstructure. The yield strength of $\mathrm{UO}_{2}$ films irradiated at $600^{\circ} \mathrm{C}$ is plotted against the CRSS induced by gas bubbles and nanocrystallites, as shown in Figure 18. The yield strength increased linearly with the CRSS, which followed the Orowan hardening mechanism. The slope of the line of best fit is known as Schmid factor [61] or Taylor factor [57, 58]. The Schmid factor from Figure 17 is 1.4, less than the value 1.8, obtained from He-bubbles in Ni [58] and $\mathrm{Al}$ precipitates in $\mathrm{Ni}$ [60]. This difference can be attributed to the loss of some implanted gases due to the recrystallization, internal stresses in the thin films, and the differences between the metallic $\mathrm{Ni}$ and the ceramic $\mathrm{UO}_{2}$.

Hardness is the material resistance to plastic deformation. Empirical observations led to a linear relationship between the hardness and yield strength in metals [62]. From this relation, the hardness of a ductile metal is found to be approximately three times its yield strength [63 - 65]. Thin films are known to be harder than their bulk sample counterparts $[56,66]$. Thus, the relationship between hardness and yield strength of thin films is expected to deviate; especially for ceramic materials. The hardness and yield strength of $\mathrm{UO}_{2}$ thin films irradiated with $600 \mathrm{keV} \mathrm{Kr}^{+}$ions at $25^{\circ} \mathrm{C}$ and $600^{\circ} \mathrm{C}$ were found to increase with dose as summarized in Table 2. The hardness plotted against the yield strength values estimated by FEM as shown in Figure 19. When a linear fit was used, the resulting slope was 1.54. These results can be used as a base to estimate the mechanical properties of thin films using the nanoindentation measurements.

Finally, these results show that elastic modulus initially decreased with irradiation at $25^{\circ} \mathrm{C}$ and $600^{\circ} \mathrm{C}$, but it increased with higher irradiation doses at both temperatures similar to Pujol et al. results [4]. In addition, the study showed that irradiation can led to recrystallization of the nuclear fuel which also has been reported in other studies [7, 8]. Therefore, this work verified that $\mathrm{UO}_{2}$ thin films can be used to obtain similar and relevant results for bulk fuel samples to understand the nuclear fuel performance in controlled experimental conditions [67 - 70] and using small scale mechanical testing $[71,72]$. 


\section{$\underline{\text { 5. Conclusions }}$}

This study focused on the change in mechanical properties of single crystal $\mathrm{UO}_{2}$ thin films under different irradiation conditions. The mechanical response of thin films of $\mathrm{UO}_{2}$ due to radiation damage and the formation of gas bubbles was investigated under irradiation with $600 \mathrm{keV} \mathrm{Kr}^{+}$ions at two different temperatures, $25^{\circ} \mathrm{C}$ and $600^{\circ} \mathrm{C}$. At $25^{\circ} \mathrm{C}$; the film hardness and yield strength were found to increase with irradiation dose due to the formation of gas bubble formation and dislocation loops. On the other hand, the elastic modulus was found to decrease at the initial irradiation dose, and then it increased with increasing the irradiation dose. When irradiation performed at $600^{\circ} \mathrm{C}$, the annealing effect was noticed mainly as a decrease in the elastic modulus due to the annihilation of point defects in the film. Both hardness and elastic modulus decreased at the lowest irradiation dose, and then they increased systematically with dose. This behavior is attributed to the formation of nanocrystallite with diameter and densities increase with dose. Although gas bubbles were formed after irradiation, but nanocrystallites represent the primary source of hardening. The film hardness was found to increase with dose and follow Orowan hardening mechanism. Finally, by comparing these results to the previous studies focusing on the mechanical properties of nuclear fuel, it was concluded that thin films can be used to get results that are similar and relevant to bulk fuel samples.

Acknowledgments

This work was performed with support from the US Department of Energy Nuclear Research Initiative under grant number DEFG-07-14891. In addition, this work was carried out in part in the Frederick Seitz Materials Research Laboratory Central Facilities, University of Illinois, which are partially supported by the US Department of Energy under grants DE-FG02-07ER46453 and DE-FG02$07 E R 46471$. 


\section{References}

[1] L. Jernkvist, A model for predicting pellet-cladding interaction-induced fuel rod failure, Nuclear Engineering and Design, Vol. 156, 393-399, 1995.

[2] V. Roque, B. Cros, D. Baron, P. Dehaudt, Effects of the porosity in uranium dioxide on microacoustic and elastic properties, Journal of Nuclear Materials, Vol. 277, 211-216, 2000.

[3] D. Laux, D. Baron, G. Despaux, A.I. Kellerbauer, M. Kinoshita, Determination of high burn-up nuclear fuel elastic properties with acoustic microscopy, Journal of Nuclear Materials, Vol. 420,94-100, 2012.

[4] M. Pujol, M. Idiri, L. Havela, S. Heathman, J. Spino, Bulk and Young's modulus of doped UO2 by synchrotron diffraction under high pressure and Knoop indentation, Journal of Nuclear Materials, Vol. 324, 189-197, 2004.

[5] D. Martin, Elastic constants of polycrystalline $\mathrm{UO} 2$ and $(\mathrm{U}, \mathrm{Pu})$ mixed oxides: a review and recommendations. High temperatures - high pressures Vol. 21.1, 13-24, 1989.

[6] J. Spino, J. Cobos-Sabate, F. Rousseau, Room-temperature microindentation behaviour of LWR fuels, part 1: fuel microhardness, Journal of Nuclear Materials, Vol. 322, 204-216, 2003.

[7] J. Spino, K. Vennix, M. Coquerelle, Detailed characterisation of the rim microstructure in PWR fuels in the burn-up range 40-67 GWd/tM, Journal of Nuclear Materials, Vol. 231, 179, 1996.

[8] Hj. Matzke, J. Spino, Formation of the rim structure in high burnup fuel, Journal of Nuclear Materials, Vol. 248, 170, 1997.

[9] S. Kim, T. Kirihara, Micro-hardness of neutron irradiated uranium dioxide at room temperature, Journal of Nuclear Science and Technology, Vol. 20, 1023, 1983.

[10] S. Kim, T. Kirihara, Indentation creep of UO2 before and after irradiation, Journal of Nuclear Science and Technology, Vol. 21, 42, 1984.

[11] W. Oliver, G. Pharr, Improved technique for determining hardness and elastic modulus using load and displacement sensing indentation experiments. Journal of materials research Vol. 7.6 1564-1580, 1992.

[12] G. Pharr, W. Oliver, F. Brotzen, On the generality of the relationship among contact stiffness, contact area, and elastic modulus during indentation. Journal of materials research, Vol. 7.3 613-617, 1992.

[13] K. Kurosaki, D. Setoyama, J. Matsunaga, S. Yamanaka, Nanoindentation tests for TiO2, MgO, and YSZ single crystals, Journal of Alloys and Compounds, Vol. 38,261-264, 2005.

[14] K. Sickafus, C. Wetteland, N. Baker, N. Yu, R. Devanathan, M. Nastasi, N. Bordes, A comparison between the irradiation damage response of spinel and zirconia due to Xe ion bombardment, Materials Science and Engineering: A, Vol. 253, 78-85, 1998.

[15] K. Sickafus, H. Matzke, K. Yasuda, P. Chodak, R. Verrall, P.Lucuta, H. Andrews, A. Turos, R. Fromknecht, N. Baker, Radiation damage effects in cubic-stabilized zirconia irradiated with $72 \mathrm{MeV}$ I+ 
ions, Nuclear Instruments and Methods in Physics Research Section B: Beam Interactions with Materials and Atoms, Vol. 141, 358-365,1998.

[16] K. Kurosaki, Y. Saito, H. Muta, M. Uno, S. Yamanaka, Nanoindentation studies of UO2 and (U,Ce)O2, Journal of Alloys and Compounds, Vol. 381, 240-244, 2004.

[17] K. Yamada, S. Yamanaka, T. Nakagawa, K. Uno, K. Katsura, Study of the thermodynamic properties of (U, Ce)O2. Journal of nuclear materials Vol. 247, 289-292, 1997.

[18] K. Yamada, S. Yamanaka, K. Katsura, Mechanical properties of (U,Ce)O2. Journal of alloys and compounds Vol. 271, 697-701, 1998.

[19] K. Kurosaki, Y. Saito, M. Uno, S. Yamanaka, Characterization of simulated burnup fuel by nanoindentation, Journal of Nuclear Materials, Vol. 350, 203-207, 2006.

[20] J. Knapp, D. Follstaedt, S. Myers, J. Barbour, T. Friedmann, Finite-Element Modeling of Nanoindentation. Journal of Applied Physics, Vol. 85.3, 1460-74, 1999.

[21] J. Knapp, D. Follstaedt, J. Barbour, S. Myers, Finite-element modeling of nanoindentation for determining the mechanical properties of implanted layers and thin films, Nuclear Instruments and Methods in Physics Research Section B: Beam Interactions with Materials and Atoms, Vol. 127-128, 935-939, 1999.

[22] O. Borrero-López, M. Hoffman, A. Bendavid, P. Martin, Substrate effects on the mechanical properties and contact damage of diamond-like carbon thin films, Diamond and Related Materials, Vol. 19, 1273-1280, 2010.

[23] S. Berg, T. Nyberg, Fundamental understanding and modeling of reactive sputtering processes, Thin Solid Films, Vol. 476, 215-230, 2005.

[24] M. Strehle, B. Heuser, M. Elbakhshwan, X. Han, D. Gennardo, H. Pappas, H. Ju, Characterization of single crystal uranium-oxide thin films grown via reactive-gas magnetron sputtering on yttria-stabilized zirconia and sapphire, Thin Solid Films, Vol. 520, 5616-5626, 2012.

[25] J. Shin, J. Lee, T. Kim, Y. No, W. Cho, W. Choi, Growth mechanisms of thin-film columnar structures in zinc oxide on p-type silicon substrates. Applied physics letters, Vol. 88.9, 091911, 2006.

[26] M. Adamik, P. Barna, I. Tomov, Columnar structures in polycrystalline thin films developed by competitive growth, Thin Solid Films, Vol. 317, 64-68,1998.

[27] Q. Tang, K. Kikuchi, S. Ogura, A. Macleod, Mechanism of columnar microstructure growth in titanium oxide thin films deposited by ion-beam assisted deposition. Journal of vacuum science \& technology. A. Vacuum, surfaces, and films, Vol. 17.6, 3379-3384, 1999.

[28] J. Matthews, A. Blakeslee, Defects in epitaxial multilayers: I. Misfit dislocations, Journal of Crystal Growth, Vol. 27, 118-125, 1974.

[29] E. Grier, M. Jenkins, A. Petford-Long, R. Ward, M. Wells, Misfit dislocations of epitaxial (110) niobium/ (1120) sapphire interfaces grown by molecular beam epitaxy. Thin solid films, Vol. 358.1, 9498, 2000. 
[30] J. Ziegler, J. Biersack, et al. SRIM - The Stopping and Range of Ions in Matter. New York: Pergamon, 1985.

[31] ABAQUS Version 6.11-1. Hibbitt, Karlsson and Sorensen, Inc., Pawtucket, RI.

[32] M. Fujikane, D. Setoyama, S. Nagao, R. Nowak, S. Yamanaka, Nanoindentation examination of yttria-stabilized zirconia (YSZ) crystal, Journal of Alloys and Compounds, Vol. 431, 250-255, 2007.

[33] Lee Van Duyn, "Evaluation of the mechanical behavior of a metal matrix dispersion fuel for plutonium burning." Diss. Georgia Institute of Technology. 2003.

[34] Y. Xiang, X. Chen, J. Vlassak, The mechanical properties of electroplated Cu thin films measured by means of the bulge test technique. Materials Research Society symposia proceedings, Vol. 695, 189-194, 2000.

[35] K. Nogita, K. Une, Radiation-induced microstructure change in high burnup UO2 fuel pellets, Nuclear Instruments and Methods in Physics Research Section B, Vol. 91, 301-306, 1994.

[36] W. Nix, Mechanical properties of thin films. Metallurgical transactions. A, Physical metallurgy and materials science, Vol. 20.11, 2217-2245, 1989.

[37] W. Chen, Y. Miao, J. Gan, M. Okuniewski, S. Maloy and J. Stubbins, Neutron irradiation effects in $\mathrm{Fe}$ and $\mathrm{Fe}-\mathrm{Cr}$ at $300^{\circ} \mathrm{C}$, Acta materialia, Vol. 111, 407-416, 2016.

[38] G. Was. Fundamentals of radiation materials science - metals and alloys. Springer, 2007.

[39] M. Makin, F. Minter, Irradiation hardening in copper and nickel, Acta Metallurgica, Vol. 8, 691-699, 1960.

[40] T. Byun, M. Li, K. Farrell. Dose Dependence of Strength After Low-Temperature Irradiation in Metallic Materials. Metallurgical and materials transactions. A, Physical metallurgy and materials science, 44.SUPPL. 1, 84-93, 2013.

[41] J. Holder, A. Granato, L. Rehn, Effects of self-interstitials and close pairs on the elastic constants of copper." Physical review. B, Solid state, Vol. 10.2,363-375, 1974.

[42] J. Melngailis, A model for change in elastic modulus of a solid caused by point defects. Physica status solidi. B, Basic research, Vol. 16.1, 247, 1966.

[43] Y. Wang, K. Duncan, E. Wachsman, F. Ebrahimi, The effect of oxygen vacancy concentration on the elastic modulus of fluorite-structured oxides, Solid State Ionics, Vol. 178, 53-58, 2007.

[44] K. Duncan, Y. Wang, S. Bishop, F. Ebrahimi, E. Wachsman, Role of Point Defects in the Physical Properties of Fluorite Oxides." Journal of the American Ceramic Society, Vol. 89.10, 3162-3166, 2006.

[45] H. Idriss, Surface reactions of uranium oxide powder, thin films and single crystals. Surface Science Reports, Vol. 65.3, 67-109, 2010.

[46] X. Wu, L. Liu, W. Li, R. Wang, Q. Liu, Effect of temperature on elastic constants, generalized stacking fault energy and dislocation cores in $\mathrm{MgO}$ and $\mathrm{CaO}$, Computational Condensed Matter, Vol. 1, 38-44, 2014. 
[47] H. Ledbetter, Sound velocities, elastic constants: Temperature dependence, Materials Science and Engineering A, Vol. 442, 31-34, 2006.

[48] A. Hall, Elastic moduli and internal friction of some uranium ceramics. Journal of nuclear materials, Vol. 37.3, 314-323, 1970.

[49] Y. Kim, G. Hofman and J. Cheon. Recrystallization and fission-gas-bubble swelling of U-Mo fuel. Journal of nuclear materials, Vol. 436.1-3, 14-22, 2013.

[50] Hj. Matzke, A. Turos, G. Linker, Polygonization of single crystals of the fluorite-type oxide UO2 due to high dose ion implantation, Nuclear Instruments and Methods in Physics Research Section B: Beam Interactions with Materials and Atoms, Vol. 91, 294-300, 1994.

[51] R. Canon, J. Roberts, R. Beals, Deformation of UO2, at high temperatures, Journal of The American Ceramic Society, Vol. 54.2, 105-112, 1971.

[52] R. Keller, T. Mitchell, A. Heuer, Plastic deformation in nonstoichiometric UO2+x single crystals-I. Deformation at low temperatures, Acta matall. Vol. 36.4, 1061-1071, 1988.

[53] K. Ashbee, C. Yust, A mechanism for the ease of slip in UO2+x, Journal of Nuclear Materials, Vol. 110, 246-250, 1982.

[54] P. Fossati, L. Brutzel, B. Devincre, Molecular dynamics simulation of dislocations in uranium dioxide, Journal of Nuclear Materials, Vol. 443, 359-365, 2013.

[55] D. Olander. Fundamental Aspects of Nuclear Reactor Fuel Elements. Virginia: Energy research and development administration, 1976.

[56] E. Nembach. Particle Strengthening of Metals and Alloys. New York: Wiley, 1997.

[57] D. Follstaedt, J. Knapp, S. Myers, Strengthening by high densities of nanometer-size precipitates: Oxides in Ni. Metallurgical and materials transactions. A, Physical metallurgy and materials science, Vol. 34 A.4, 935-949, 2003.

[58] J. Knapp, D. Follstaedt, S. Myers, Hardening by bubbles in He-implanted Ni. Journal of applied physics, Vol. 103.1, 013518, 2008.

[59] A. Hall, Elastic moduli and internal friction of some uranium ceramics. Journal of nuclear materials, Vol. 37.3, 314-323, 1970.

[60] N. Li, M. Nastasi, A. Misra, Defect structures and hardening mechanisms in high dose helium ion implanted $\mathrm{Cu}$ and $\mathrm{Cu} / \mathrm{Nb}$ multilayer thin films, International Journal of Plasticity, Vol. 32-33, 1-16, 2012.

[61] J. Hirth, J. Lothe, Theory of dislocations. New York, McGraw-Hill, 1968.

[62] D. Tabor, Hardness of Metals. Clarendon Press, Oxford, 1951.

[63] Y. Cheng, C. Cheng, What is indentation hardness?, Surface and Coatings Technology, Vol. 133134, 417-424, 2000. 
[64] K. Lee, C. Yeo, A. Polycarpou, Relationship between scratch hardness and yield strength of elastic perfectly plastic materials using finite element analysis. Journal of Materials Research, Vol. 23(8), 2229$2237,2008$.

[65] R. Katta, Dynamic and quasi-static contact and scratch analysis of micro-nanoscale thin solid films with application to magnetic storage hard disk drives. Diss. U. of Illinois. 2009.

[66] Y. Xiang, X. Chen, J. Vlassak, The mechanical properties of electroplated Cu thin films measured by means of the bulge test technique. Materials Research Society symposia proceedings, Vol. 695, 189-194, 2000 .

[67] A. Adamska, R. Springell, A. Warren, L. Picco, O. Payton, T. Scott, Growth and characterization of uranium-zirconium alloy thin films for nuclear industry applications, Journal of Physics D: Applied Physics, Vol. 47, 315301, 2014.

[68] A. Adamska, R. Springell, T. Scott, Characterization of poly- and single-crystal uraniummolybdenum alloy thin films, Thin Solid Films, Vol. 550, 319-325, 2014.

[69] A. Adamska, W. Liu, J. Sutcliffe, E. Bright, "A new thin-film approach to making nuclear fuel research accessible" in Uranium: Sources, exposure and environmental effects. Nova Science Publishers, 253-262, 2015.

[70] B. Scott, J. Joyce, T. Durakiewicz, R. Martin, T. McCleskey, E. Bauer, H. Luo, Q. Jia, High quality epitaxial thin films of actinide oxides, carbides, and nitrides: Advancing understanding of electronic structure of f-element materials, Coordination Chemistry Reviews, Vol. 266-267, 137-154, 2014.

[71] P. Hosemann, C. Shin, D. Kiener, Small scale mechanical testing of irradiated materials, Journal of Materials Research, Vol. 30.9, 1231-1245, 2015.

[72] D. Kiener, A. Minor, O. Anderoglu, Y. Wang, S. Maloy, P. Hosemann, Application of small-scale testing for investigation of ion-beam-irradiated materials, Journal of Materials Research, Vol. 27.21, 2724-2736, 2012. 
Table 1. Irradiation parameters for $\mathrm{Kr}^{+}$ions.

\begin{tabular}{|c|c|c|c|c|c|}
\hline Ion & Energy (keV) & Range $(\AA)$ & $\begin{array}{c}\text { Dose } \\
\text { (ions } / \mathrm{cm}^{2} \text { ) }\end{array}$ & $\begin{array}{c}\text { Average atomic } \\
\text { concentration (at. \%) }\end{array}$ & $\begin{array}{c}\text { Average } \\
\text { dpa }\end{array}$ \\
\hline \multirow{6}{*}{$\mathrm{Kr}^{+}$} & \multirow{6}{*}{600} & \multirow{6}{*}{1629} & $1 \mathrm{E} 14$ & 0.02 & $<1$ \\
\hline & & & $5 \mathrm{E} 14$ & 0.10 & 4 \\
\hline & & & $1 \mathrm{E} 15$ & 0.2 & 8 \\
\hline & & & $5 \mathrm{E} 15$ & 1.01 & 43 \\
\hline & & & $1 \mathrm{E} 16$ & 2.03 & 86 \\
\hline & & & $1.5 \mathrm{E} 16$ & 3.04 & 130 \\
\hline
\end{tabular}

Table 2. FEM estimation of the elastic modulus, yield strength, and hardness of untreated, annealed, and irradiated $5000 \AA \mathrm{UO}_{2}$ thin films irradiated with $600 \mathrm{keV} \mathrm{Kr}^{+}$ions at $25^{\circ} \mathrm{C}$ and $600^{\circ} \mathrm{C}$.

\begin{tabular}{|c|c|c|c|c|}
\hline $\begin{array}{c}\text { Dose } \\
\left(\text { ions } / \mathrm{cm}^{2}\right)\end{array}$ & $\begin{array}{c}\text { Temperature } \\
\left({ }^{\circ} \mathrm{C}\right)\end{array}$ & $\begin{array}{c}\text { Elastic } \\
\text { modulus }(\mathrm{GPa})\end{array}$ & $\begin{array}{c}\text { Yield strength } \\
(\mathrm{GPa})\end{array}$ & $\begin{array}{c}\text { Hardness } \\
(\mathrm{GPa})\end{array}$ \\
\hline Reference & 25 & 180 & 7.5 & 13.5 \\
\hline $1 \mathrm{E} 14$ & 25 & 165 & 8.5 & 14.2 \\
\hline $5 \mathrm{E} 14$ & 25 & 170 & 9.7 & 14.9 \\
\hline $1 \mathrm{E} 15$ & 25 & 167 & 9.5 & 14.5 \\
\hline $5 \mathrm{E} 15$ & 25 & 170 & 9.7 & 14.9 \\
\hline $1 \mathrm{E} 16$ & 25 & 175 & 9.8 & 15.3 \\
\hline Annealed & 600 & 160 & 7.2 & 12.5 \\
\hline $1 \mathrm{E} 14$ & 600 & 145 & 7.0 & 11.6 \\
\hline $1 \mathrm{E} 15$ & 600 & 155 & 7.5 & 12.5 \\
\hline $5 \mathrm{E} 15$ & 600 & 165 & 8.2 & 13.6 \\
\hline $1 \mathrm{E} 16$ & 600 & 175 & 9.2 & 14.8 \\
\hline $1.5 \mathrm{E} 16$ & 600 & 178 & 10.0 & 15.5 \\
\hline
\end{tabular}


Table 3. Bubbles size, density, and the critical resolved shear stress for $\mathrm{UO}_{2}$ films irradiated with $600 \mathrm{keV}$ $\mathrm{Kr}^{+}$ions at $25^{\circ} \mathrm{C}$.

\begin{tabular}{|c|c|c|c|}
\hline Dose & Bubble diameter $(\mathrm{nm})$ & Bubble density $\left(\mathrm{nm}^{-3}\right)$ & CRSS (GPa) \\
\hline $1 \mathrm{E} 14$ & $1.18 \pm 0.1$ & $5.8 \mathrm{E}-6$ & 0.2652 \\
\hline $5 \mathrm{E} 14$ & $1.18 \pm 0.1$ & $9.6 \mathrm{E}-6$ & 0.2835 \\
\hline $1 \mathrm{E} 15$ & $1.18 \pm 0.1$ & $3.4 \mathrm{E}-5$ & 0.3021 \\
\hline $5 \mathrm{E} 15$ & $1.18 \pm 0.1$ & $8.3 \mathrm{E}-5$ & 0.5326 \\
\hline $1 \mathrm{E} 16$ & $1.18 \pm 0.1$ & $1.4 \mathrm{E}-4$ & 0.6928 \\
\hline
\end{tabular}

Table 4. Nanocrystallites and bubbles sizes, densities, and the critical resolved shear stress for $\mathrm{UO}_{2}$ films irradiated with $600 \mathrm{keV} \mathrm{Kr}^{+}$ions at $600^{\circ} \mathrm{C}$ with different irradiation doses.

\begin{tabular}{|c|c|c|c|c|c|c|}
\hline \multirow{2}{*}{ Dose } & \multicolumn{3}{|c|}{ Nanocrystallites } & \multicolumn{3}{c|}{ Bubbles } \\
\cline { 2 - 7 } & $\begin{array}{c}\text { diameter } \\
(\mathrm{nm})\end{array}$ & $\begin{array}{c}\text { density }(\mathrm{nm}- \\
3\end{array}$ & $\begin{array}{c}\text { CRSS } \\
(\mathrm{GPa})\end{array}$ & $\begin{array}{c}\text { diameter } \\
(\mathrm{nm})\end{array}$ & $\begin{array}{c}\text { density }\left(\mathrm{nm}^{-}\right. \\
3\end{array}$ & $\begin{array}{c}\text { CRSS } \\
(\mathrm{GPa})\end{array}$ \\
\hline $1 \mathrm{E} 14$ & $3 \pm 0.5$ & $1.8 \mathrm{E}-4$ & 3.865 & $0.7 \pm 0.07$ & $7.3 \mathrm{E}-5$ & 0.2116 \\
\hline $1 \mathrm{E} 15$ & $1.4 \pm 0.5$ & $3.4 \mathrm{E}-4$ & 4.734 & $0.7 \pm 0.07$ & $4.0 \mathrm{E}-5$ & 0.142 \\
\hline $5 \mathrm{E} 15$ & $1.7 \pm 0.5$ & $4.3 \mathrm{E}-4$ & 5.314 & $0.7 \pm 0.07$ & $2.1 \mathrm{E}-5$ & 0.105 \\
\hline $1 \mathrm{E} 16$ & $2 \pm 0.5$ & $5.4 \mathrm{E}-4$ & 5.730 & $0.7 \pm 0.07$ & $8.6 \mathrm{E}-6$ & 0.0644 \\
\hline $1.5 \mathrm{E} 16$ & $2 \pm 0.5$ & $5.5 \mathrm{E}-4$ & 5.812 & $0.7 \pm 0.07$ & $7.9 \mathrm{E}-6$ & 0.0621 \\
\hline
\end{tabular}




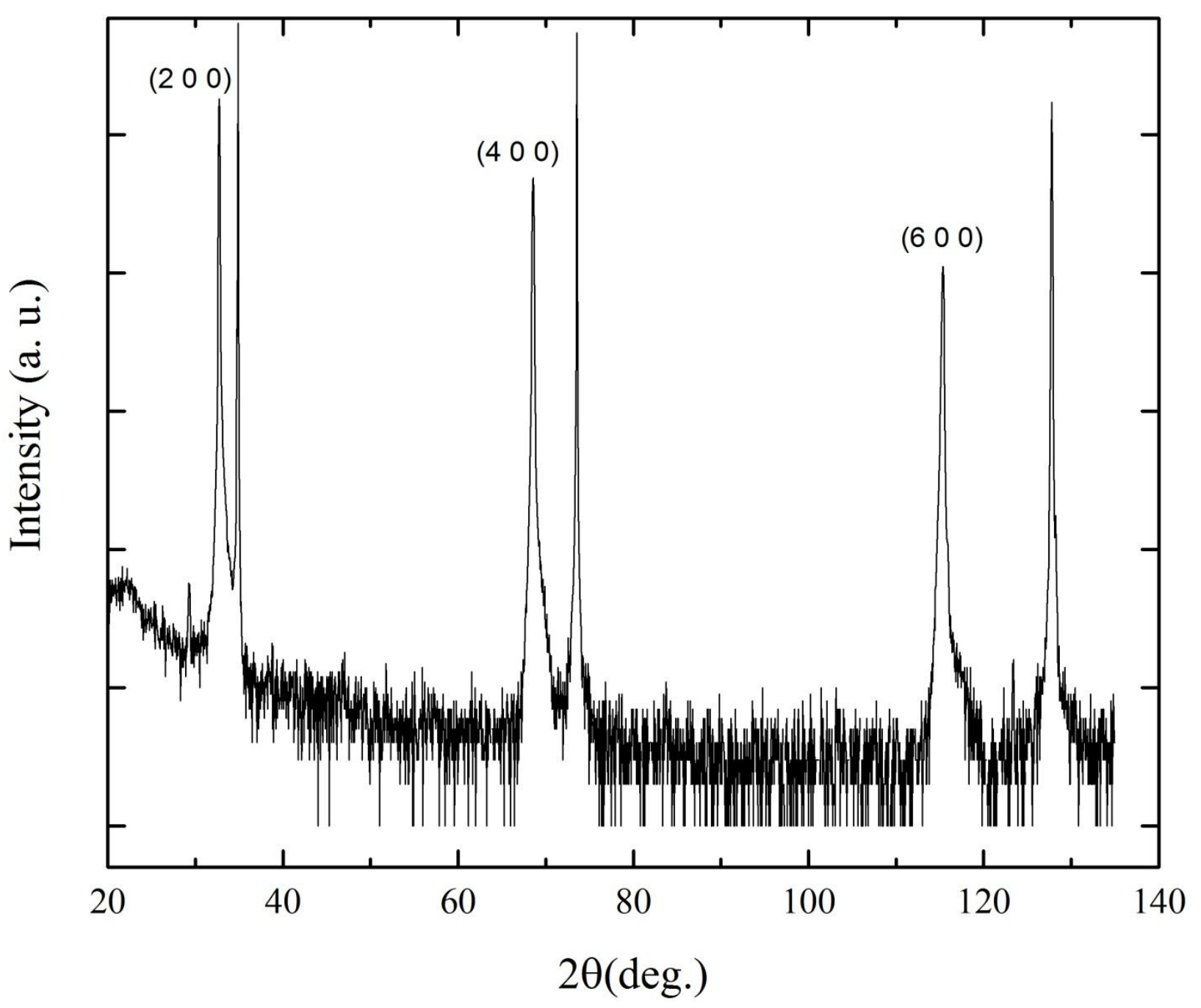

Figure 1. Indexed specular $2 \theta-\Omega$ scan for $5000 \AA \mathrm{UO}_{2}$ film deposited on YSZ substrate. 


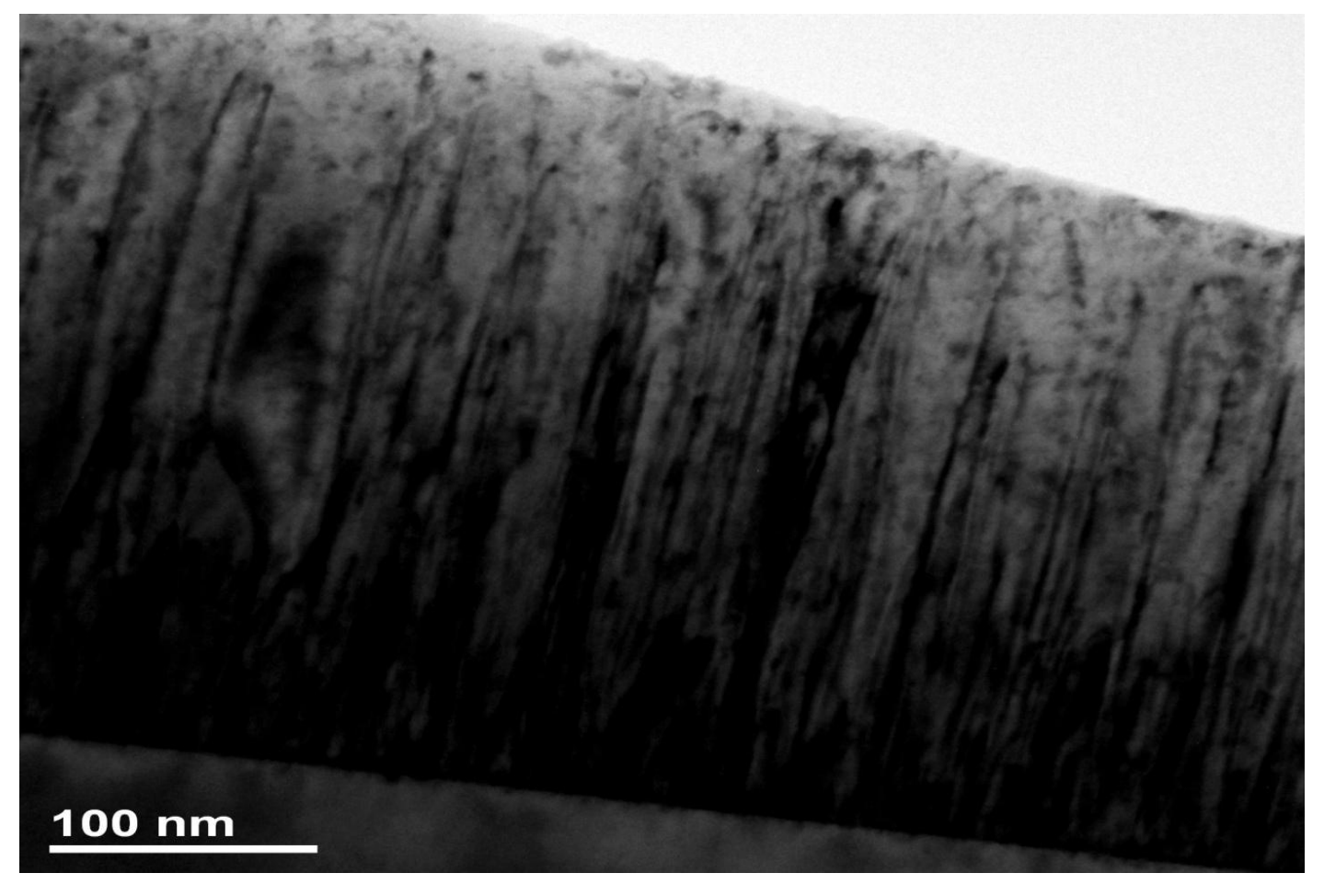

Figure 2. Bright-field cross sectional TEM image for sample 49. The image shows the columnar grains of the $\mathrm{UO}_{2}$ thin film above the substrate. 


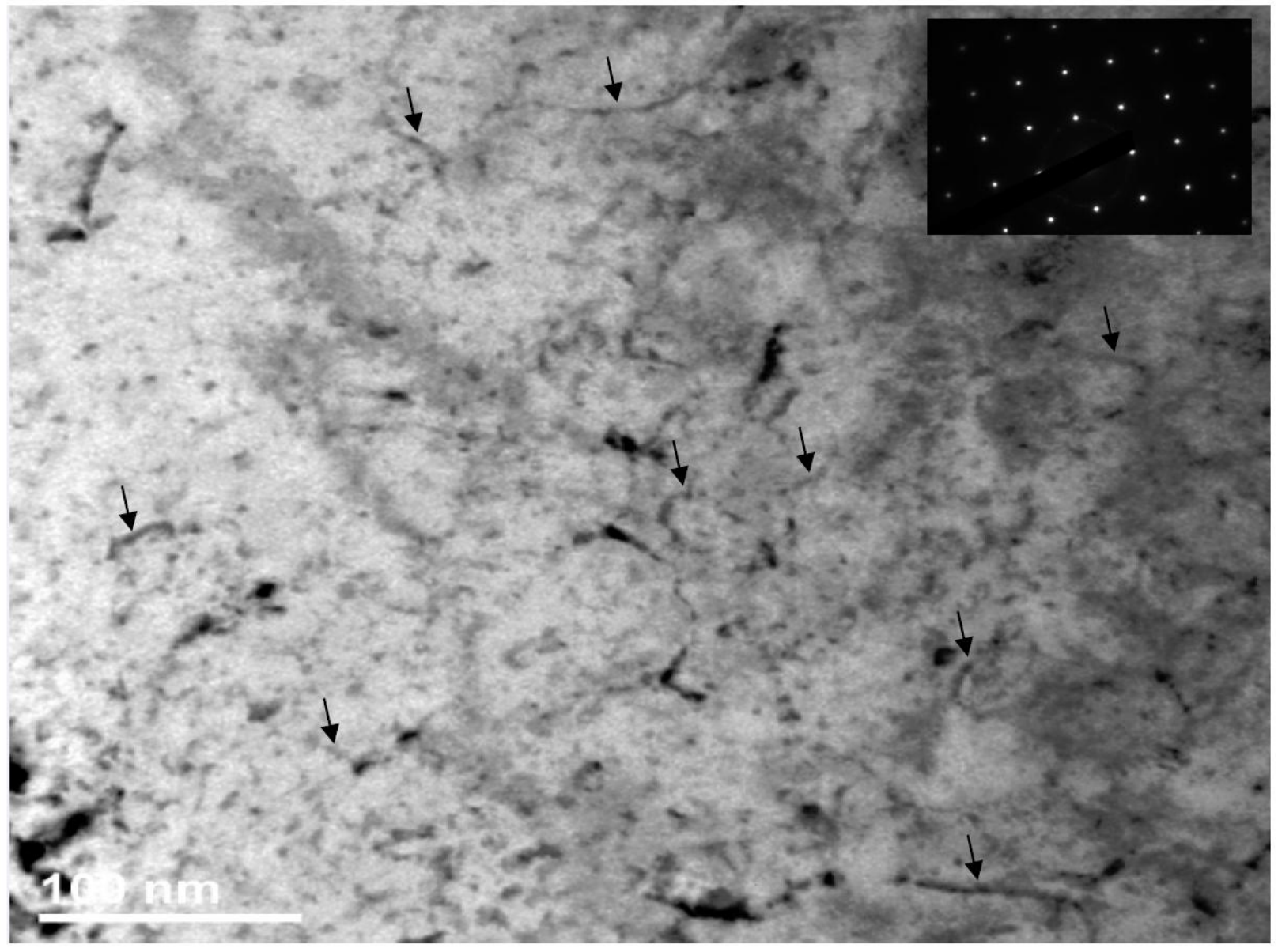

Figure 3. Bright-field, under focus and plan view TEM image for as-grown $\mathrm{UO}_{2}$ thin film. Black arrows are pointing to dislocation lines. 


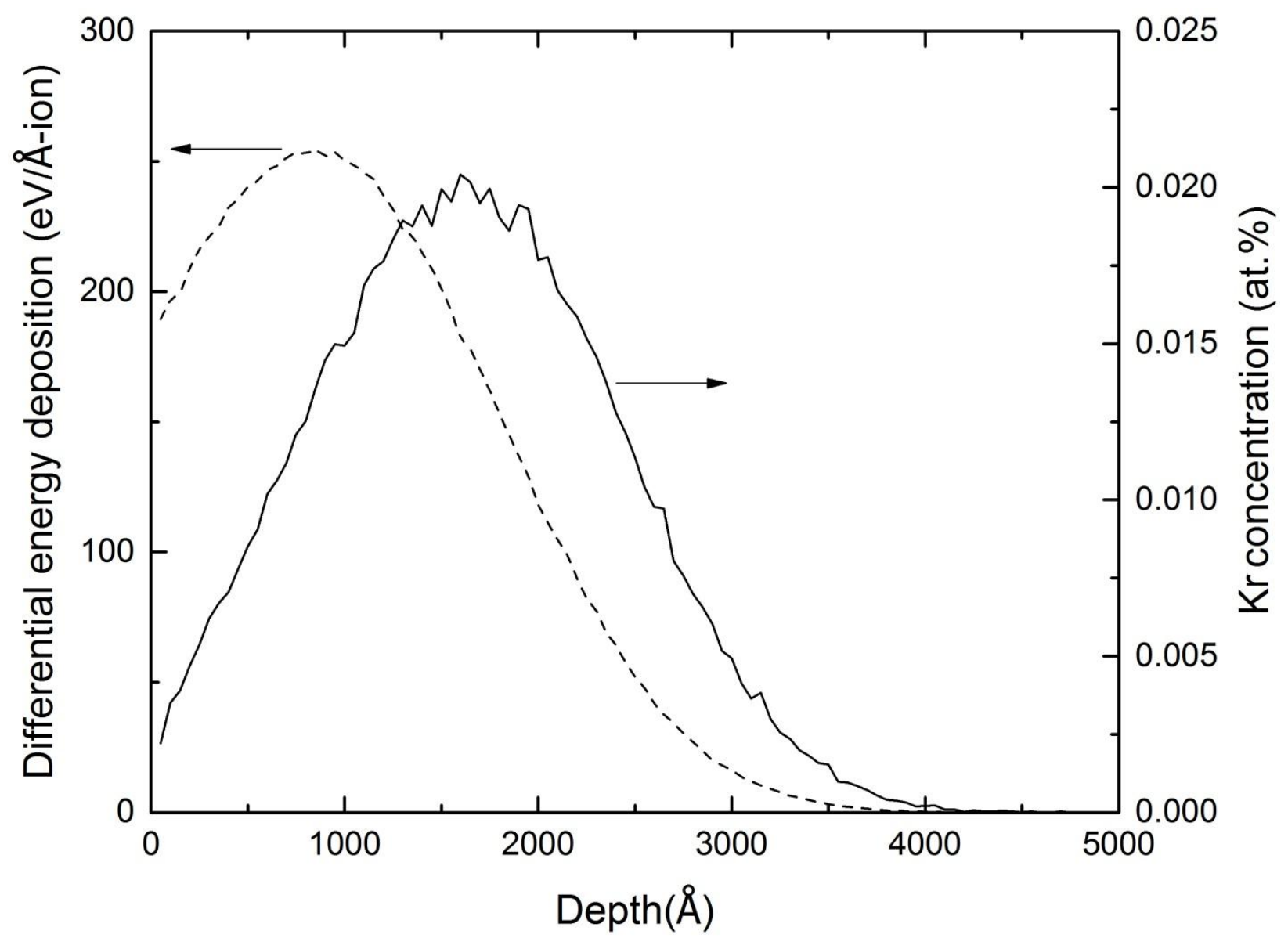

Figure 4. $\mathrm{Kr}^{+}$concentrations (dark line) and differential energy deposition (dotted line) in $5000 \AA \mathrm{UO}_{2}$ thin film irradiated with $600 \mathrm{keV} \mathrm{Kr}^{+}$ions at dose of $1 \mathrm{E} 14$ ions $/ \mathrm{cm}^{2}$. 


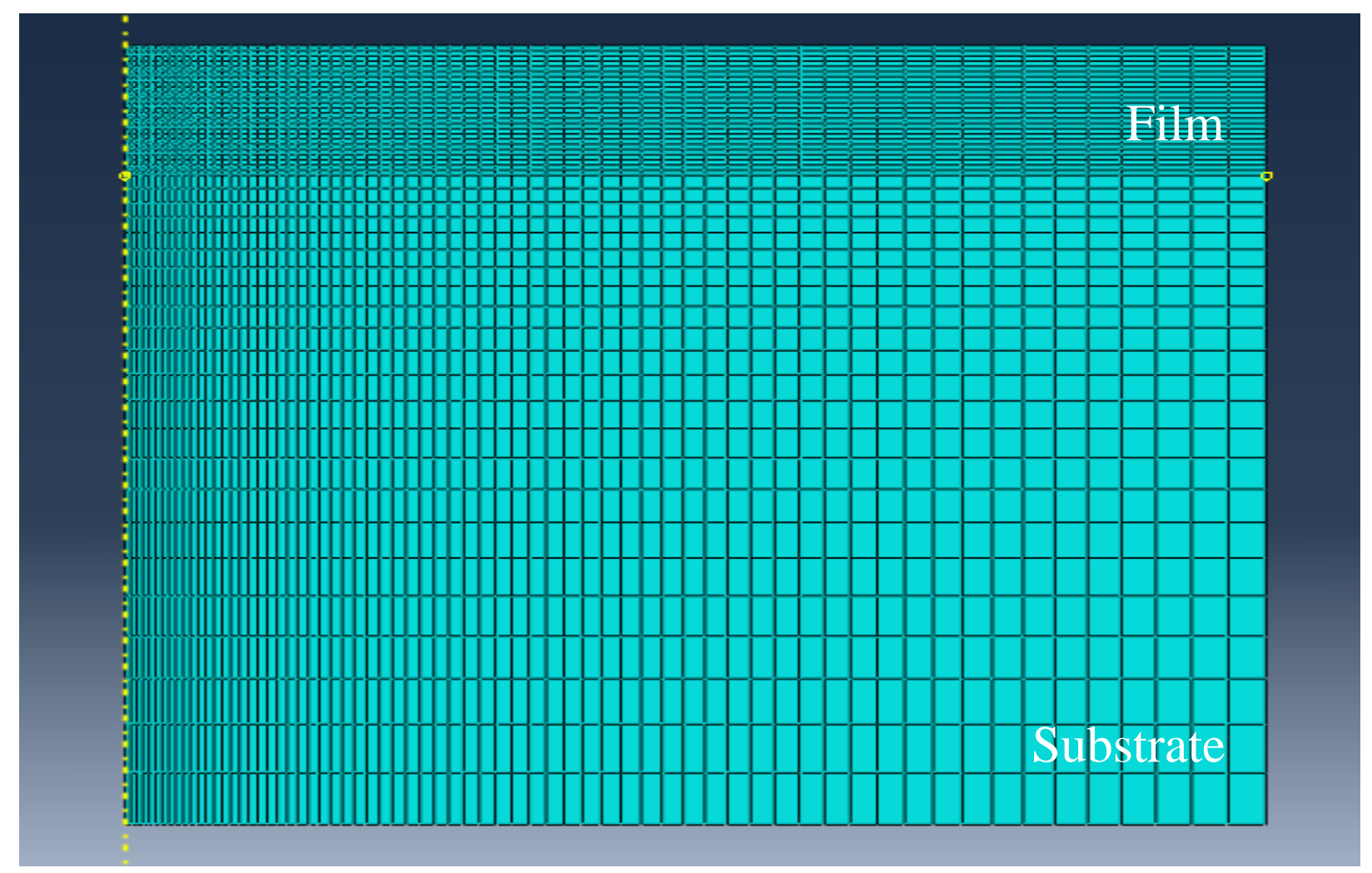

Figure 5. Elements distribution throughout the film-substrate unit. 


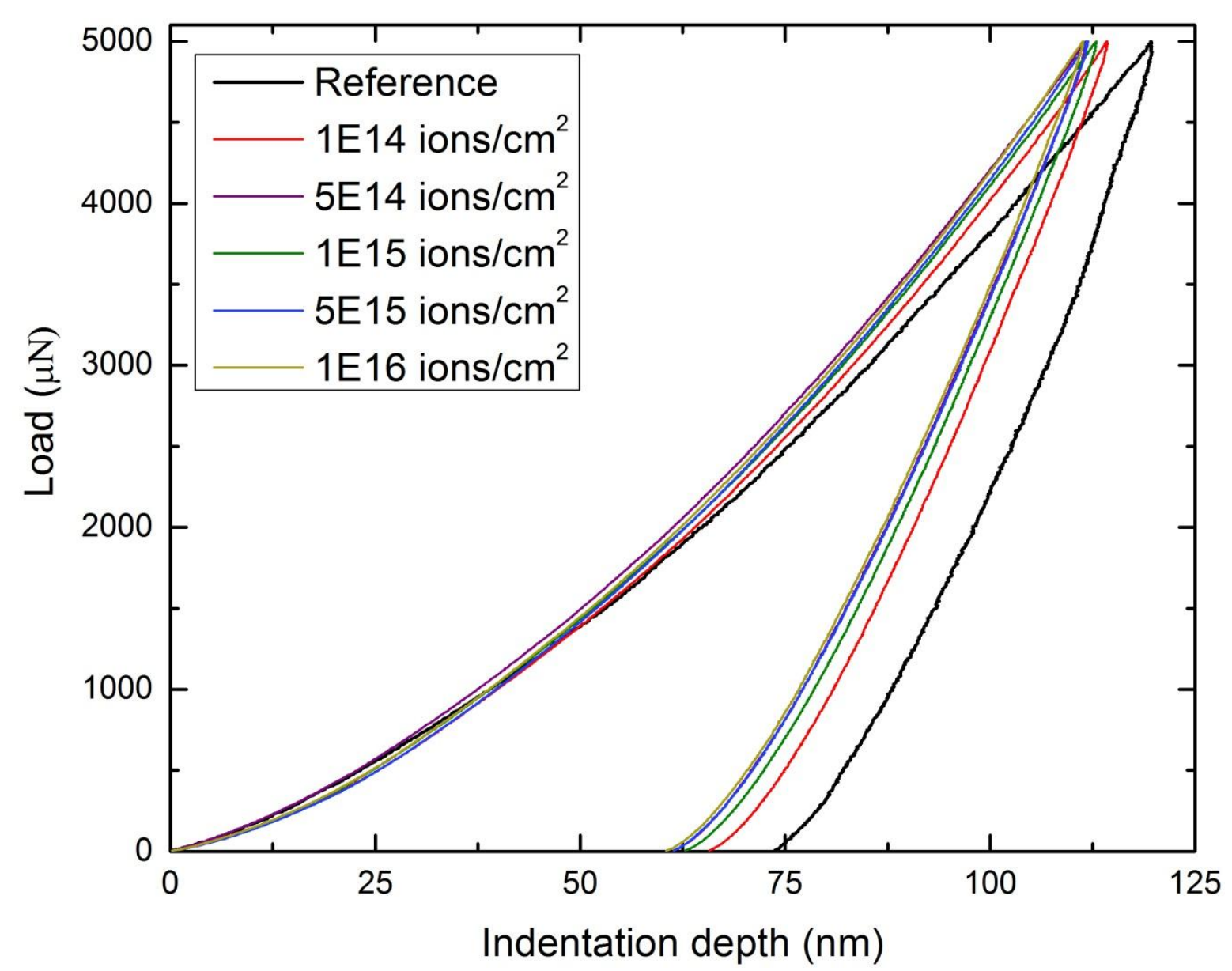

Figure 6. Load - displacement curve for $\mathrm{UO}_{2}$ thin films deposited on YSZ substrate and irradiated with $600 \mathrm{keV} \mathrm{Kr}^{+}$ions at $25^{\circ} \mathrm{C}$ with different irradiation doses. 


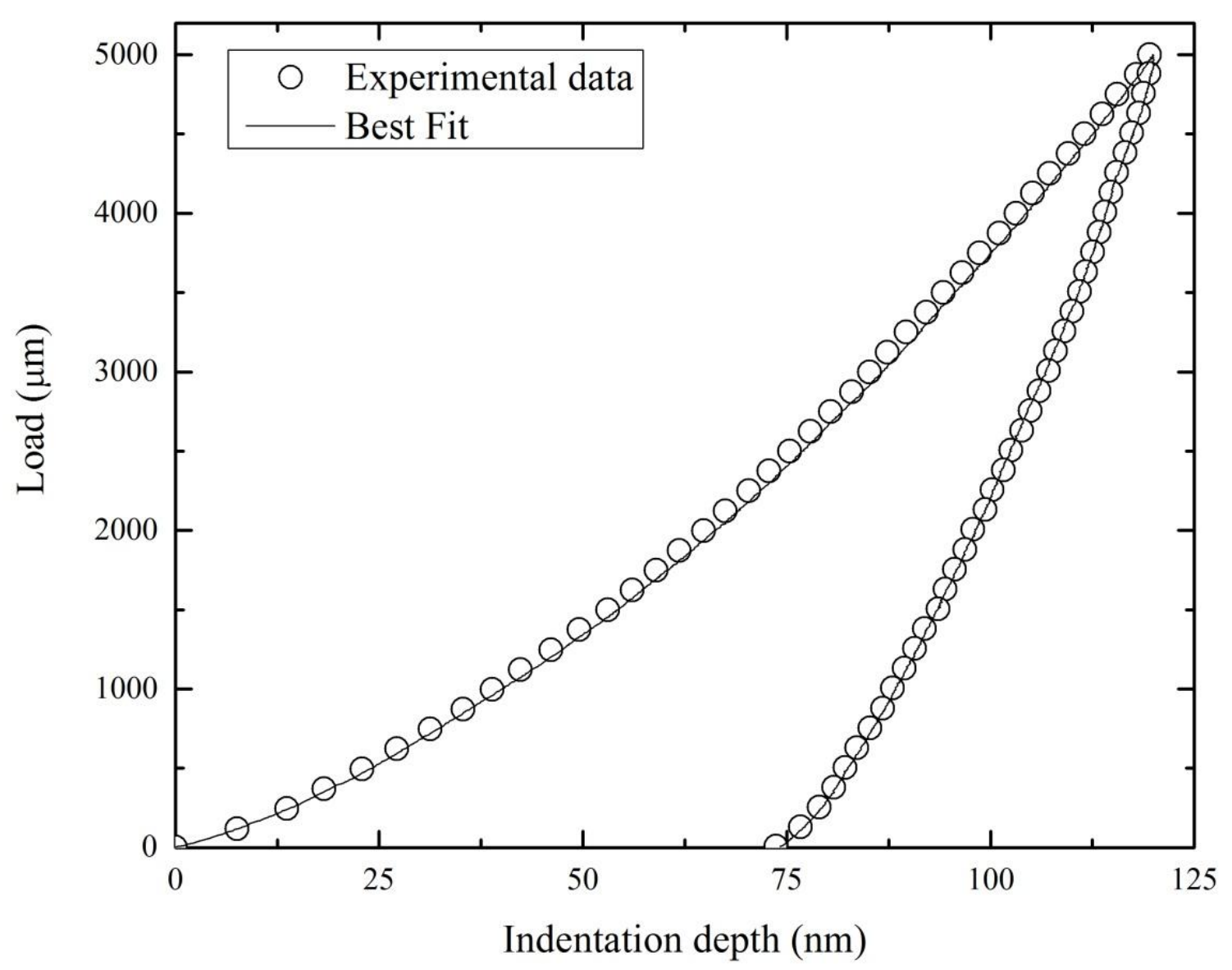

Figure 7. Best FEM fitting for load - displacement curve for $5000 \AA \mathrm{UO}_{2}$ thin films deposited on YSZ substrate. 


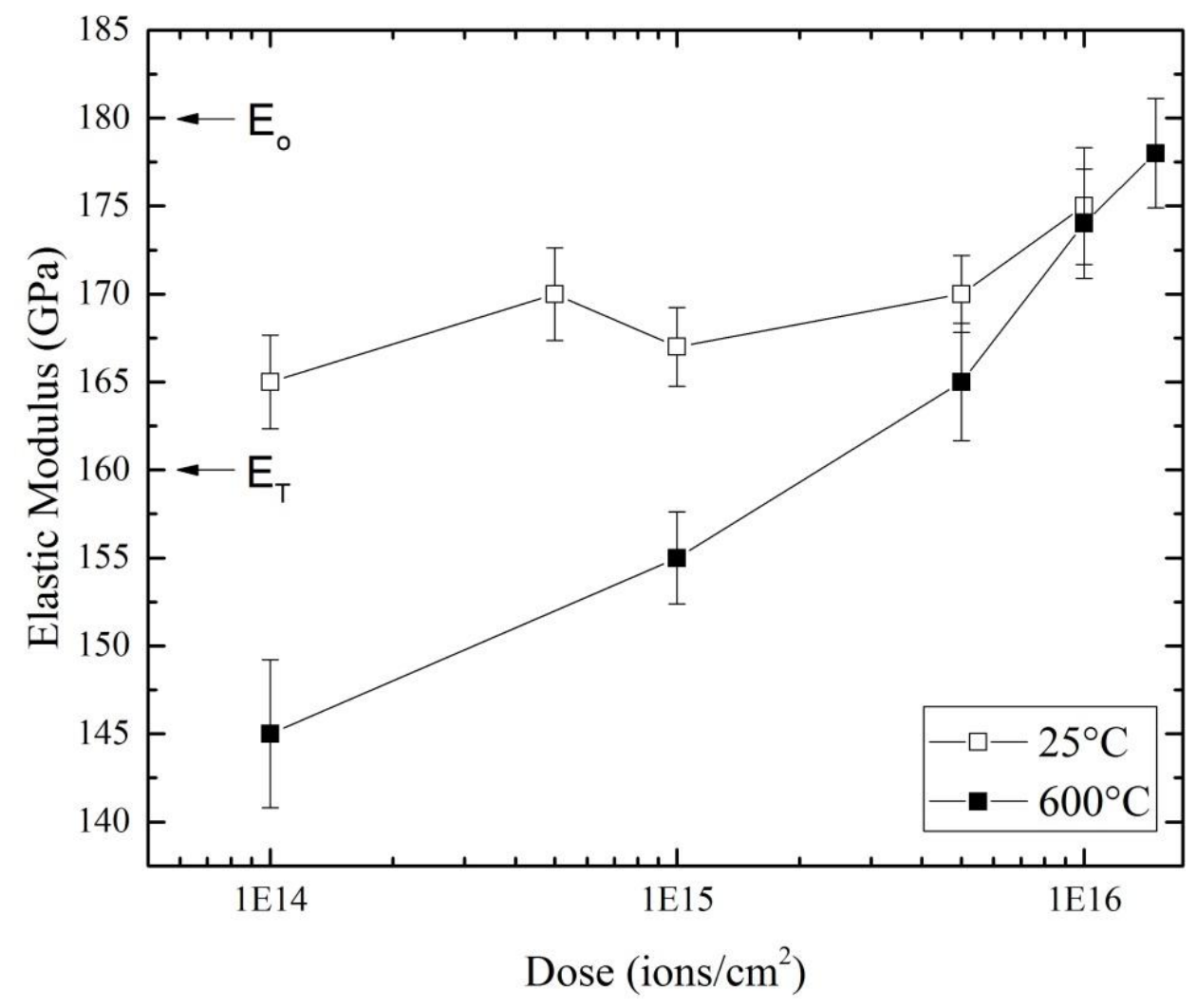

Figure 8. FEM estimation of the elastic modulus versus dose for $\mathrm{UO}_{2}$ thin films irradiated with $600 \mathrm{keV}$ $\mathrm{Kr}^{+}$ions at both $25^{\circ} \mathrm{C}$ and $600^{\circ} \mathrm{C}$. $\mathrm{E}_{\mathrm{o}}$ and $\mathrm{E}_{\mathrm{T}}$ are the elastic modulus of the untreated and the annealed samples respectively. The error bars will represent the standard deviation in the nanoindentation elastic modulus measurements. 


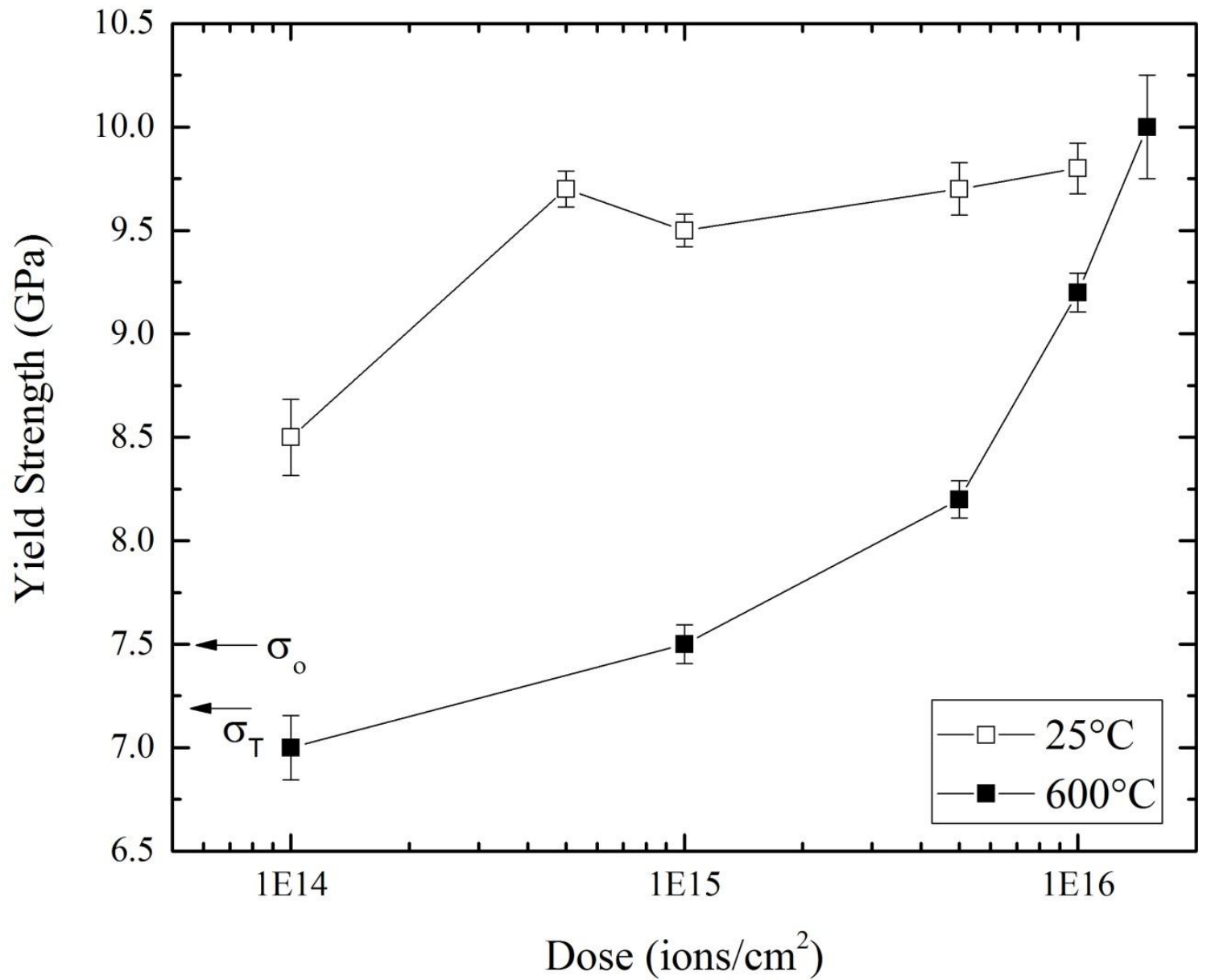

Figure 9. FEM estimation of the yield strength versus dose for $\mathrm{UO}_{2}$ films irradiated with $600 \mathrm{keV} \mathrm{Kr}^{+}$ ions at both $25^{\circ} \mathrm{C}$ and $600^{\circ} \mathrm{C} . \sigma_{\mathrm{o}}$ and $\sigma_{\mathrm{T}}$ are the yield strength of the untreated and the annealed samples respectively. The error bars will represent the standard deviation in the nanoindentation hardness measurements. 


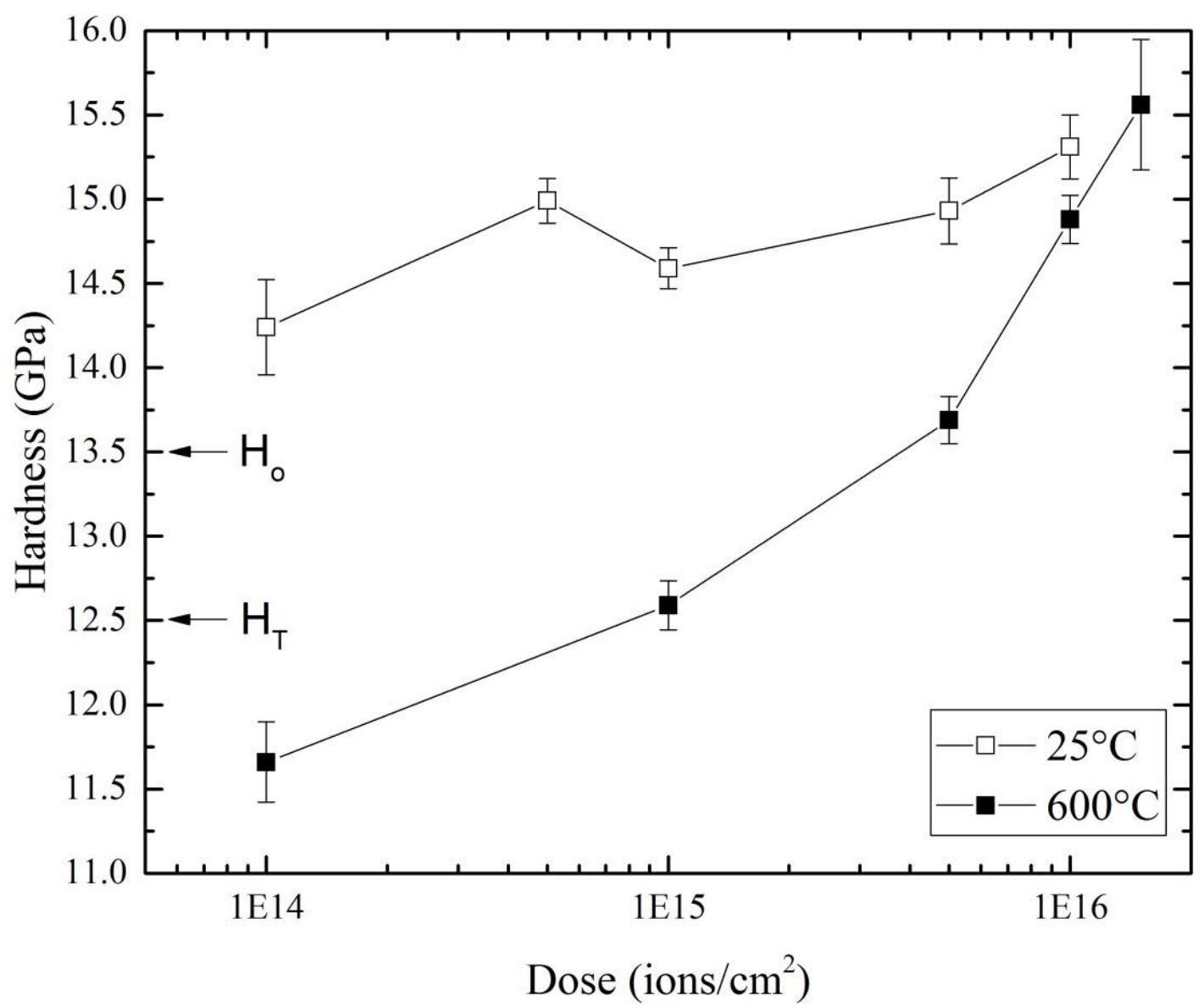

Figure 10. FEM estimation of the hardness versus irradiation dose for $\mathrm{UO}_{2}$ films irradiated with $600 \mathrm{keV}$ $\mathrm{Kr}^{+}$ions at both $25^{\circ} \mathrm{C}$ and $600^{\circ} \mathrm{C} . \mathrm{H}_{\mathrm{o}}$ and $\mathrm{H}_{\mathrm{T}}$ are the hardness of the untreated and the annealed samples respectively. The error bars will represent the standard deviation in the nanoindentation hardness measurements. 

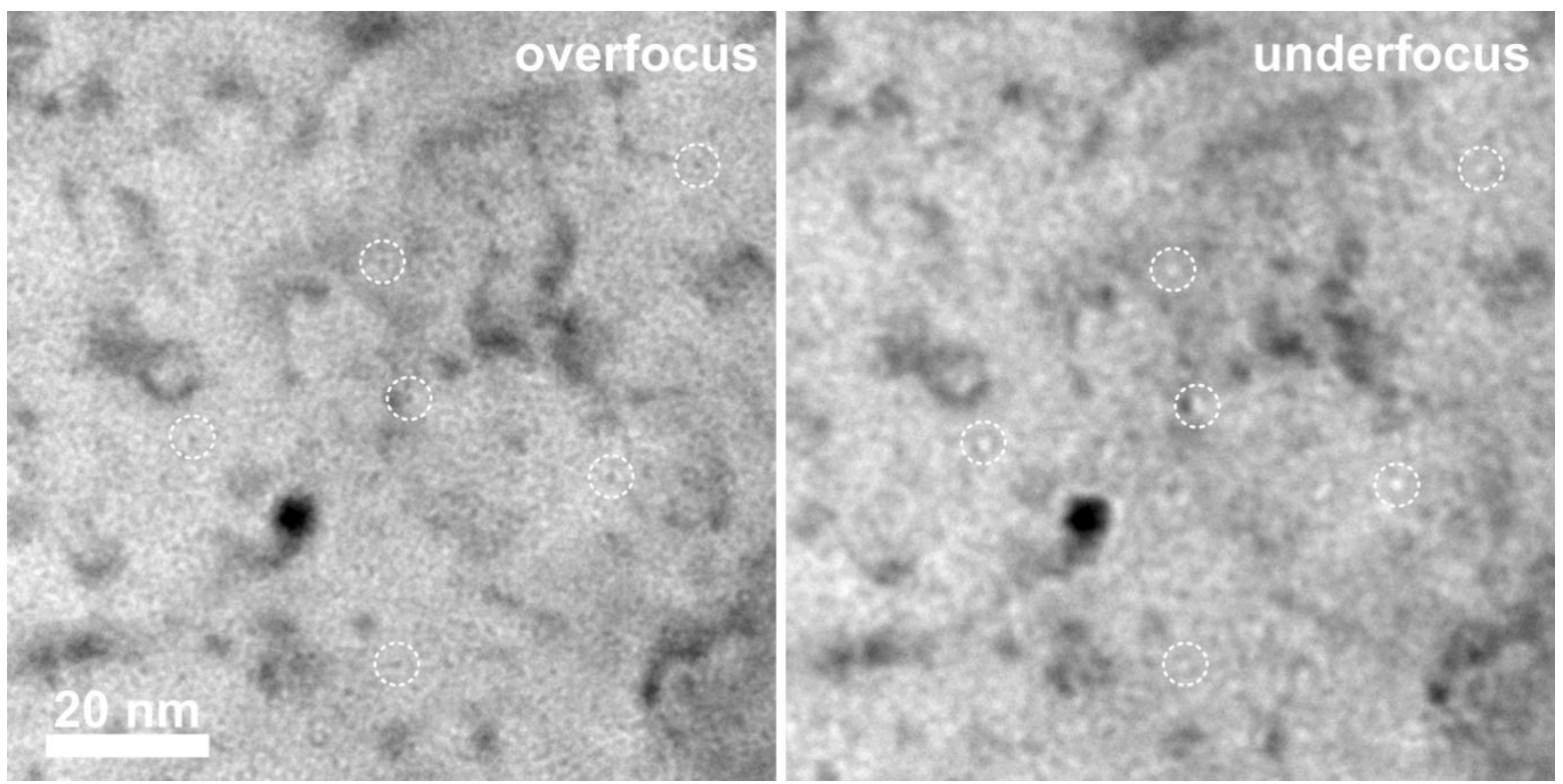

Figure 11. Plane view TEM images for $\mathrm{UO}_{2}$ thin film irradiated with $600 \mathrm{keV} \mathrm{Kr}^{+}$ions at a dose of $1 \mathrm{E} 16$ ions $/ \mathrm{cm}^{2}$ at $25^{\circ} \mathrm{C}$. Under and over focused conditions showed the voids that are surrounded by dotted white circles for visualization. 


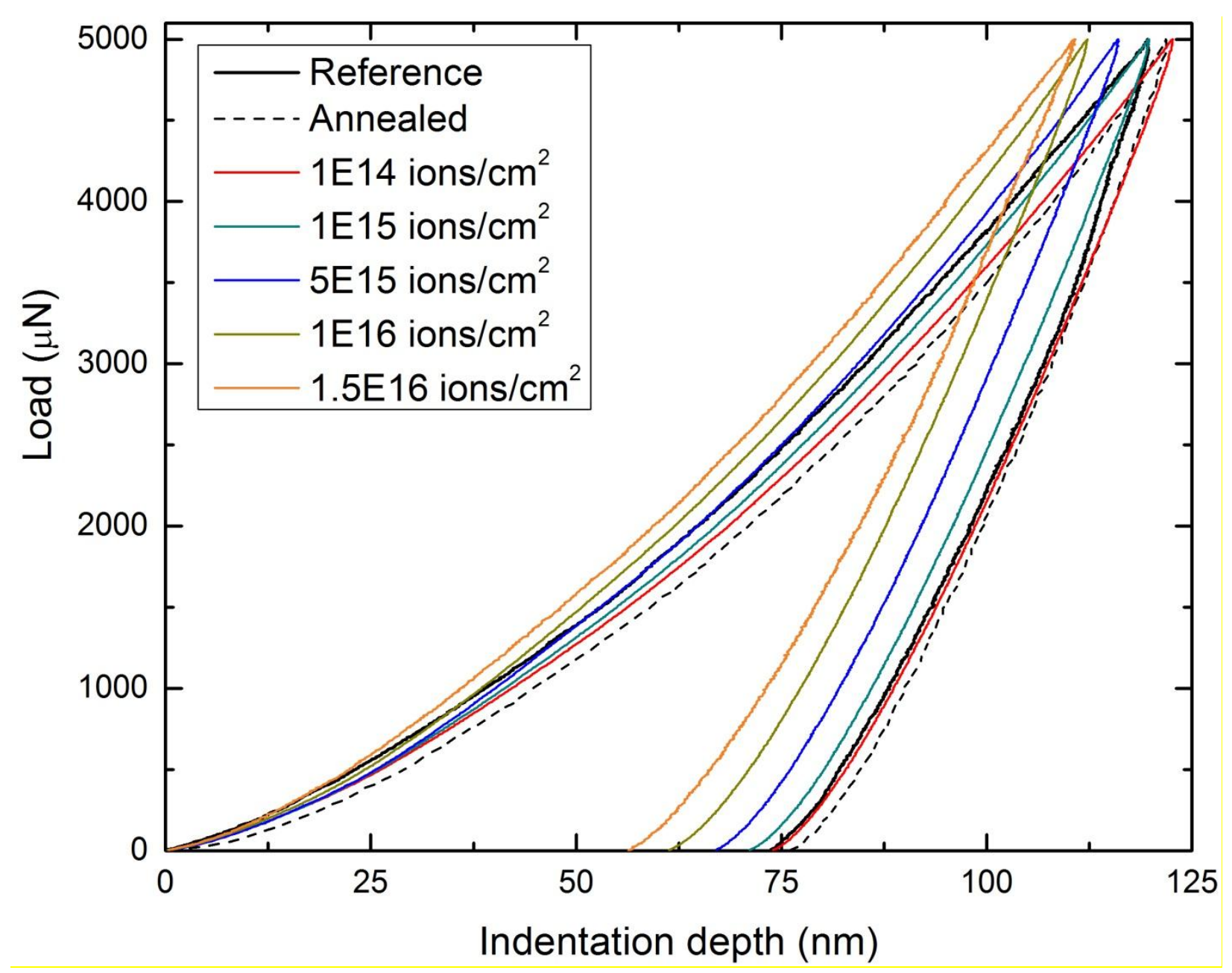

Figure 12. Load - displacement curve for $\mathrm{UO}_{2}$ thin films deposited on YSZ substrate and irradiated with $600 \mathrm{keV} \mathrm{Kr}{ }^{+}$ions at $600^{\circ} \mathrm{C}$ with different irradiation doses. 


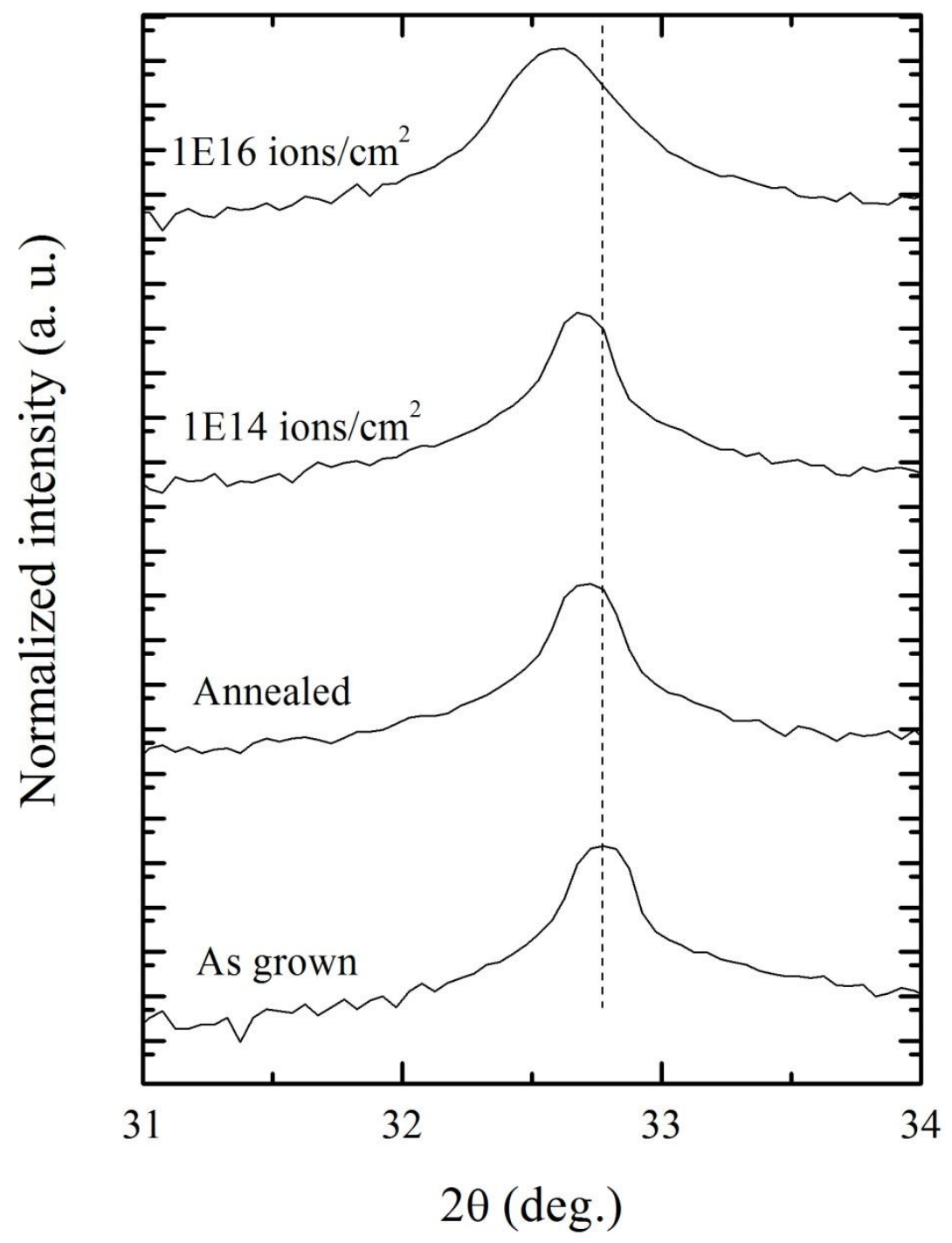

Figure 13. The development of the (200) $\mathrm{UO}_{2}$ reflection for as-grown, annealed at $600^{\circ} \mathrm{C}$, irradiated with $600 \mathrm{keV} \mathrm{Kr}+$ ions at $600^{\circ} \mathrm{C}$ with $1 \mathrm{E} 14$ and IE16 ions $/ \mathrm{cm}^{2}$. The dotted line shows the original peak position of the as-grown film. 


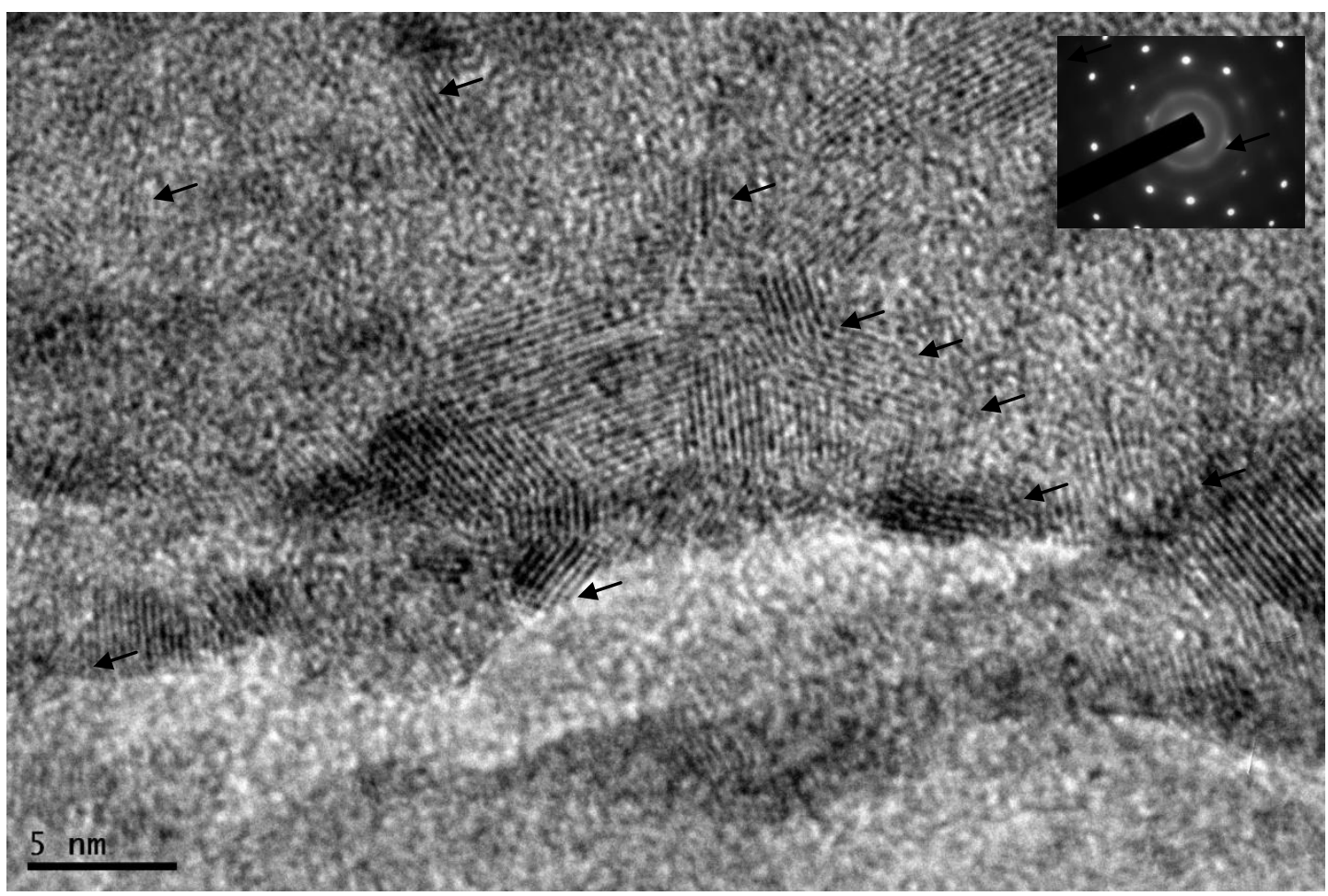

Figure 14. Plan view image for UO2 film irradiated with $600 \mathrm{keV} \mathrm{Kr}+$ ions at $600^{\circ} \mathrm{C}$ with $1 \mathrm{E} 14 \mathrm{ions} / \mathrm{cm}^{2}$. The arrows pointed to different nanocrystallites. 


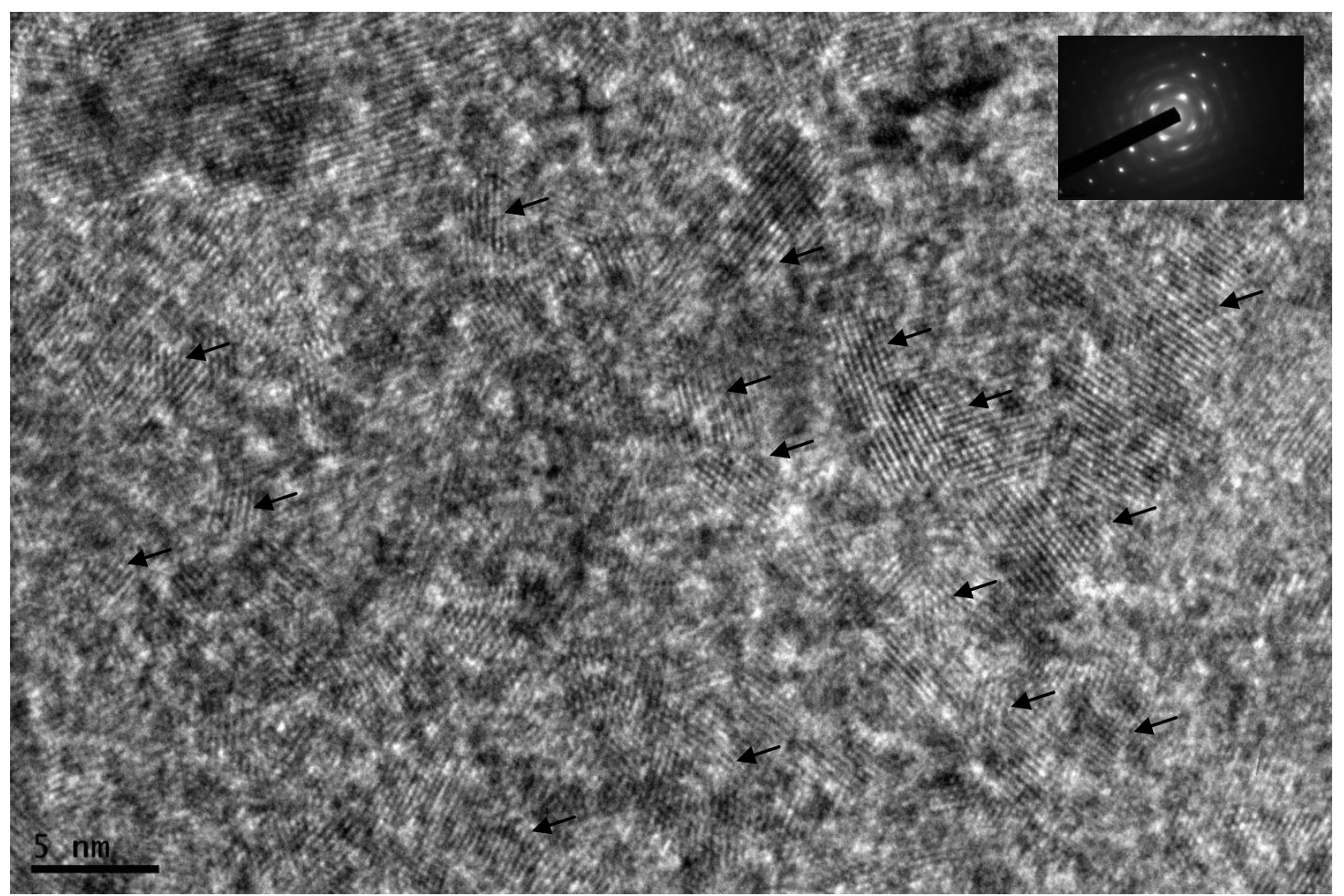

Figure 15. Plan view image for $\mathrm{UO}_{2}$ film irradiated with $600 \mathrm{keV} \mathrm{Kr}{ }^{+}$ions at $600^{\circ} \mathrm{C}$ with $1 \mathrm{E} 16$ ions $/ \mathrm{cm}^{2}$. The arrows pointed to different nanocrystallites. 

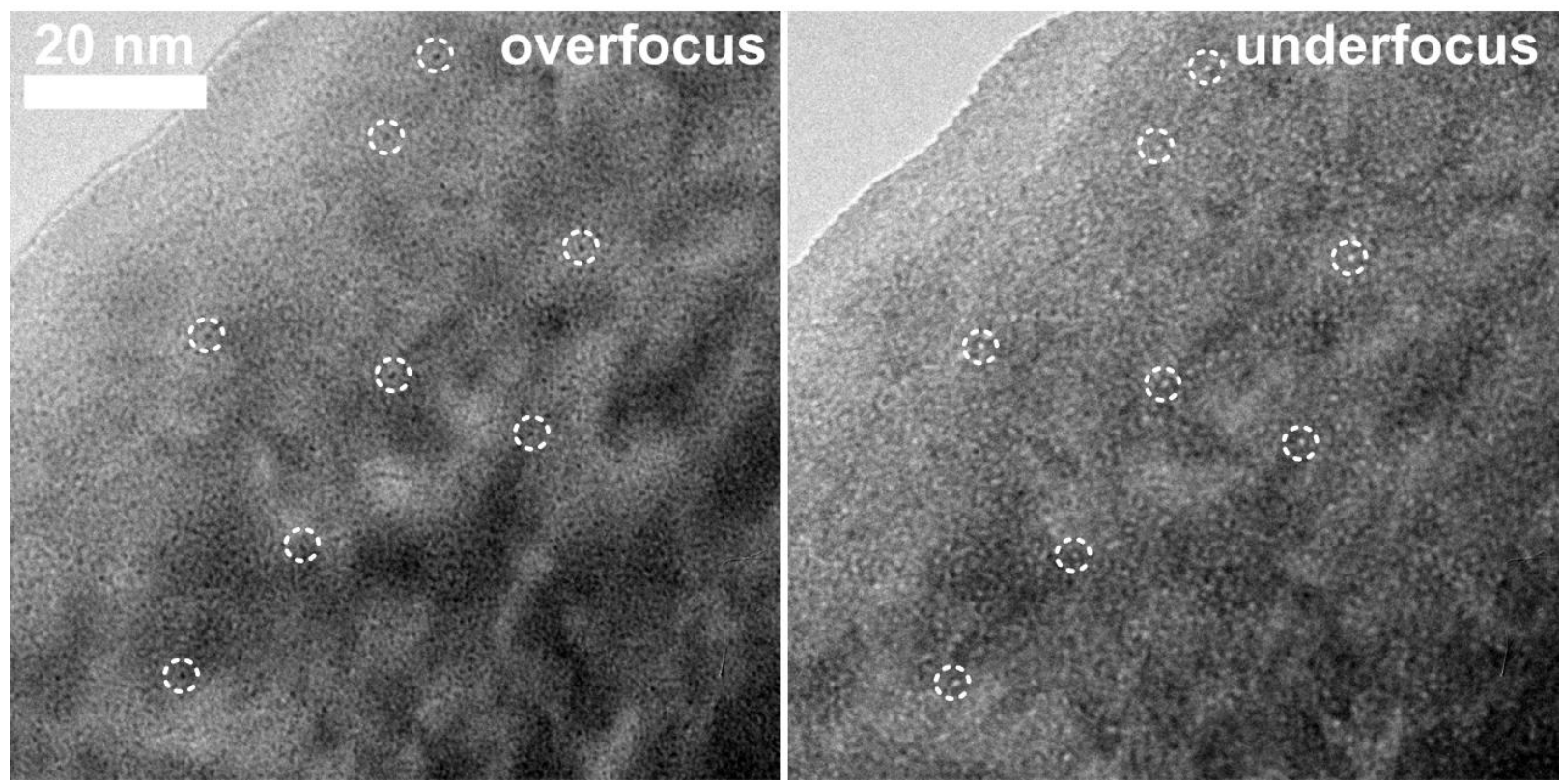

Figure 16. Plane view TEM images for $\mathrm{UO}_{2}$ thin film irradiated with $600 \mathrm{keV} \mathrm{Kr}^{+}$ions at a dose of $1 \mathrm{E} 14$ ions $/ \mathrm{cm}^{2}$ at $600^{\circ} \mathrm{C}$. Under and over focused conditions showed the voids that are surrounded by dotted white circles for visualization. 


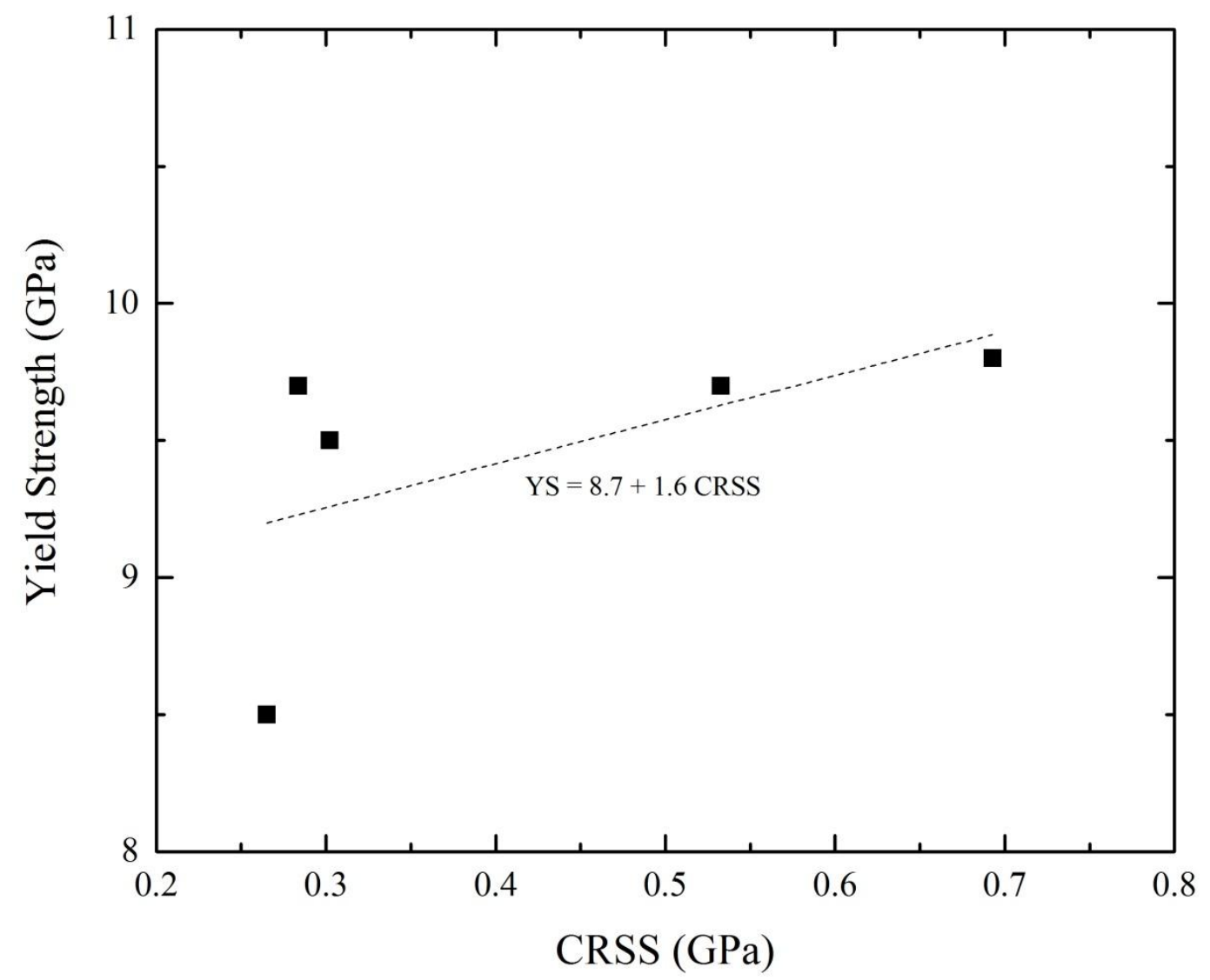

Figure 17. Yield strength of $5000 \AA \mathrm{UO}_{2}$ thin films versus CRSS evaluated using Orowan hardening mechanism due to the presence of bubbles after irradiation with $600 \mathrm{keV} \mathrm{Kr}{ }^{+}$ions at $25^{\circ} \mathrm{C}$. 


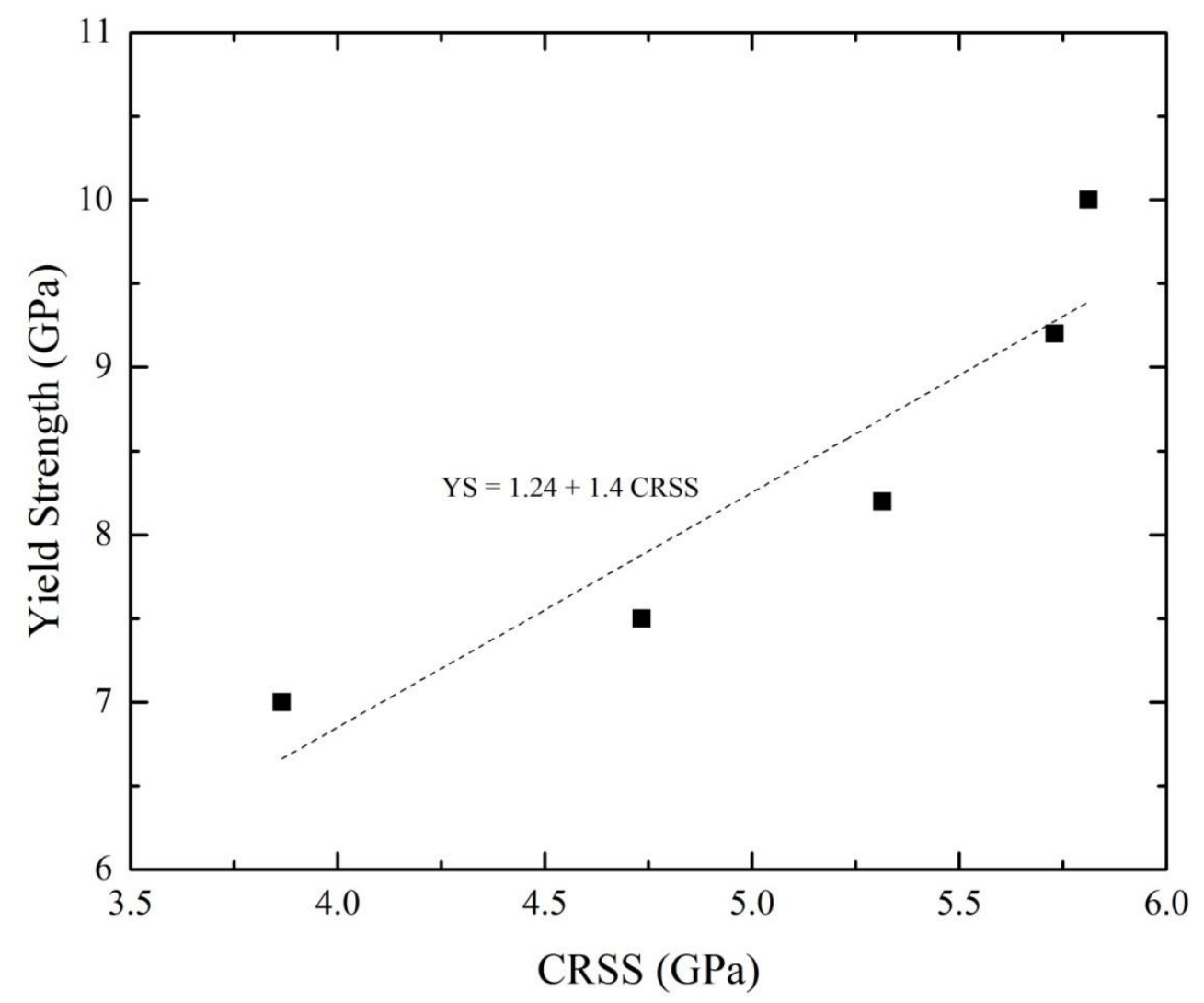

Figure 18. Yield strength of $5000 \AA \mathrm{UO}_{2}$ thin films versus CRSS evaluated using Orowan hardening mechanism due to the presence of nanocrystallites after irradiation with $600 \mathrm{keV} \mathrm{Kr}{ }^{+}$ions at $600^{\circ} \mathrm{C}$. 


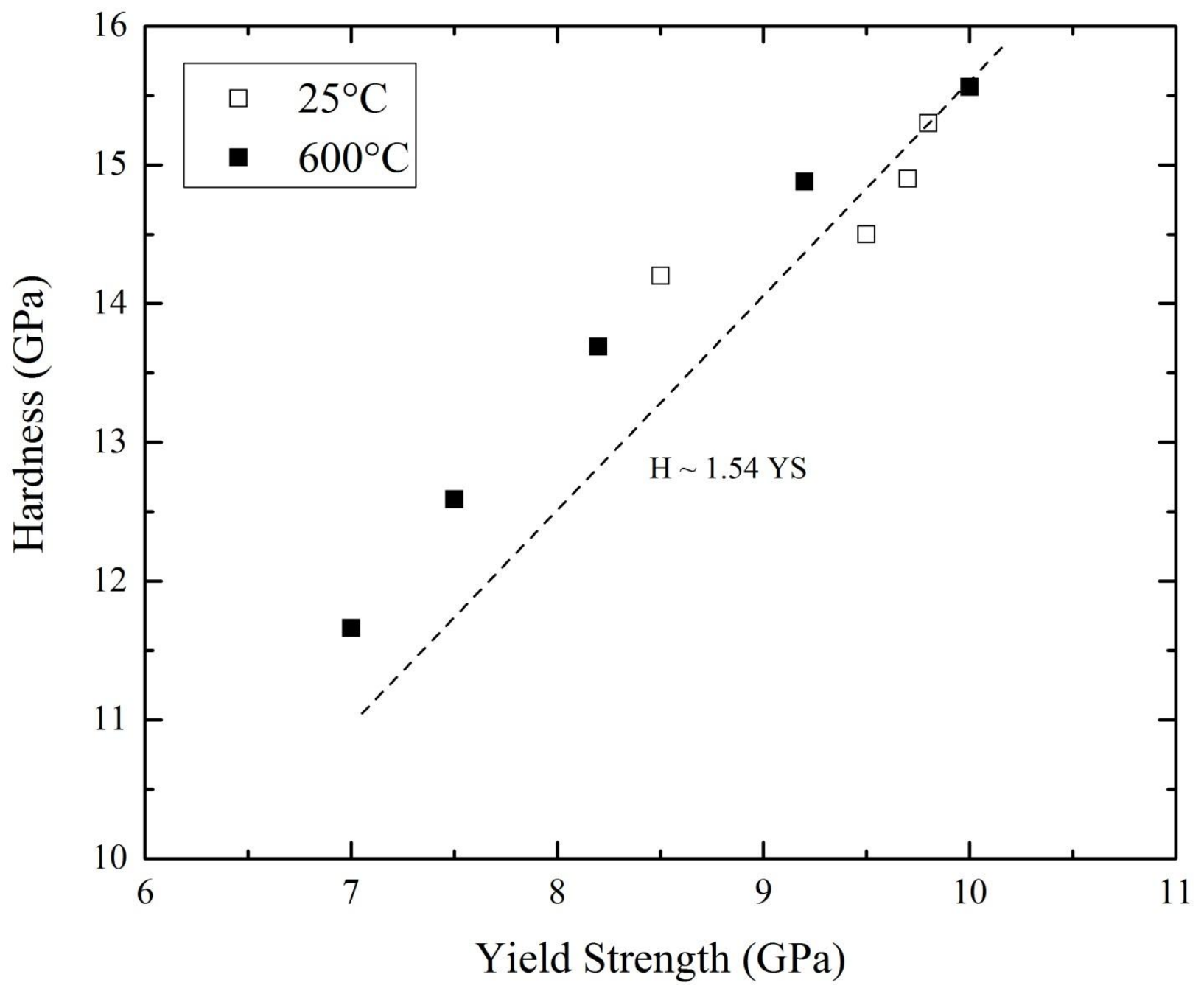

Figure 19. Hardness versus yield strength for $\mathrm{UO}_{2}$ films irradiated with $600 \mathrm{keV} \mathrm{Kr}{ }^{+}$ions at $600^{\circ} \mathrm{C}$. 